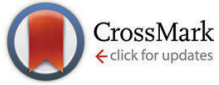

Cite this: Soft Matter, 2016, 12,7883

Received 2nd August 2016, Accepted 24th August 2016

DOI: $10.1039 / c 6 s m 01772 j$

www.rsc.org/softmatter

\section{The dependency of twist-bend nematic liquid crystals on molecular structure: a progression from dimers to trimers, oligomers and polymers}

\author{
Richard J. Mandle
}

This article gives an overview on recent developments concerning the twist-bend nematic phase. The twist-bend nematic phase has been discussed as the missing link between the uniaxial nematic mesophase $(\mathrm{N})$ and the helical chiral nematic phase $\left(\mathrm{N}^{*}\right)$. After an introduction discussing the key physical properties of the $\mathrm{N}_{\text {TB }}$ phase and the methods used to identify the twist-bend nematic mesophase this review focuses on structure property relationships and molecular features that govern the incidence of this phase.

\section{Introduction}

"Liquid crystal" is an umbrella term for a group of partially ordered, sometimes fluid, states of matter that exists in addition to the three 'common' states of matter, these being the solid, liquid and gaseous states. In addition to being the presently dominant display technology various liquid-crystalline (LC) mesophases are formed by DNA, ${ }^{1-6}$ carbohydrates and lipids, ${ }^{7-9}$ and peptides. ${ }^{10-12}$ Liquid-crystalline phases also occur on length scales beyond those of molecular dimensions, with mesophases being formed by (for example) suspensions of viral particles. ${ }^{13-15}$

The uniaxial nematic phase is the simplest LC phase and possesses only an average orientational ordering of the molecules along a preferred direction (the director). The addition of chirality to a nematic LC, either through changes to molecular structure or via the addition of a supplementary chiral dopant to the host nematic phase, leads to the formation of a helical superstructure in the nematic phase (denoted $\mathrm{N}^{*}$, chiral nematic or cholesteric). For both bent-core liquid crystals and liquid-crystalline dimers an additional possibility exists; this being the formation of a mesophase with a helical local structure and thus locally chiral, formed by materials that are themselves achiral. Such a mesophase, termed the twist-bend nematic $\left(\mathrm{N}_{\mathrm{TB}}\right.$, Fig. 1) was predicted by Dozov ${ }^{16}$ to be formed by bent molecules and was later confirmed experimentally. ${ }^{17}$ This mesophase has been described as the "structural link" between the uniaxial nematic phase and the helical chiral nematic mesophase. ${ }^{18}$ It is well known that $\mathrm{N}_{\mathrm{TB}}$ phase is exhibited by both bent-core ${ }^{19}$ and liquid-crystalline dimers, ${ }^{17}$ however, no examples of twist-bend mesophases in rod-like (calamitic) liquid-crystalline materials are known and it is presently an

Department of Chemistry, University of York, York, YO10 5DD, UK.

E-mail: richard.mandle@york.ac.uk

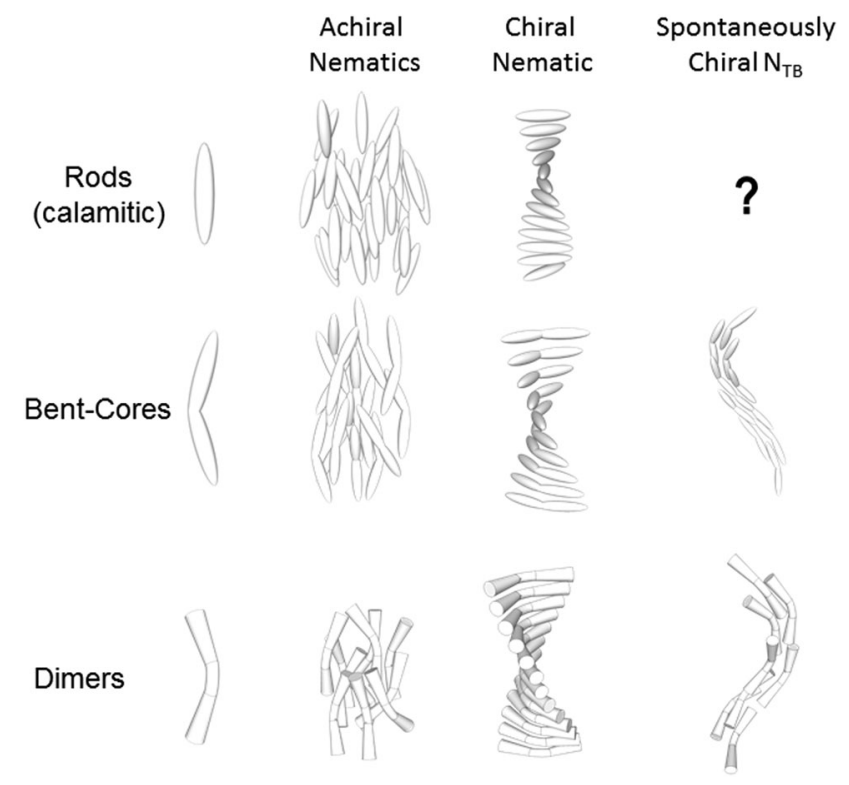

Fig. 1 General molecular structures of rod-like, bent-core and dimer liquid crystals along with cartoon depictions of the achiral nematic $(\mathrm{N})$, chiral nematic $\left(N^{*}\right)$ and spontaneously chiral $N_{\text {TB }}$ mesophases exhibited by these general structures.

open question whether or not such molecular structures can exhibit this unique mesophase.

Questions and reports concerning spontaneous breaking of mirror symmetry are of fundamental importance to a wide range of scientific disciplines ${ }^{20-29}$ and so the formation of helical, chiral, nanoscale structures in liquid-crystalline bent-core compounds, ${ }^{30-32}$ dimers ${ }^{33-36}$ and trimers ${ }^{27,37-39}$ has prompted extensive study. When formed from a racemates or molecules lacking stereogenic centre it is the chirality that results from conformers that leads to the spontaneous breaking 
of mirror symmetry in the $\mathrm{N}_{\mathrm{TB}}$ phase. For each chiral conformer there exists its mirror image, which has the opposite sign of chirality and, in the absence of a biasing chiral dopant or environment, there exists equal probabilities of each of these and thus the bulk structure is achiral. ${ }^{34}$ Despite a number of theoretical treatments ${ }^{16,36,40-43}$ and comparative studies between experiment and theory, ${ }^{44-46}$ a general and comprehensive structure property relationship remains elusive to date, aside from the widely acknowledged requirement for a 'bent' molecular shape. ${ }^{47}$

\section{Mesophase structure, physical properties and identification}

The pitch length of the helical structure of the $\mathrm{N}_{\mathrm{TB}}$ phase is on the order of several nanometres and has been measured directly by freeze-fracture transmission electron microscopy (FFTEM, Fig. 2) 18,19,48,49 $^{1}$ and resonant carbon K-edge small angle X-ray scattering (SAXS) ${ }^{50}$ as well as indirectly, with measurement of the electroclinic effect ${ }^{51}$ and ${ }^{2} \mathrm{H}$ NMR spectroscopy ${ }^{33}$ revealing the presence of an extremely short (i.e. several nanometers) helical pitch $\left(\mathrm{P}_{\mathrm{TB}}\right)$. In the case of resonant SAXS experiments the ability to measure the $\mathrm{P}_{\mathrm{TB}}$ in situ has allowed the temperature dependence of the pitch to be determined quantitatively for the first time. ${ }^{50}$ It is unfortunate that to date these techniques have only been applied to a small number of molecules, and so it is unknown how $\mathrm{P}_{\mathrm{TB}}$ varies with molecular structure.

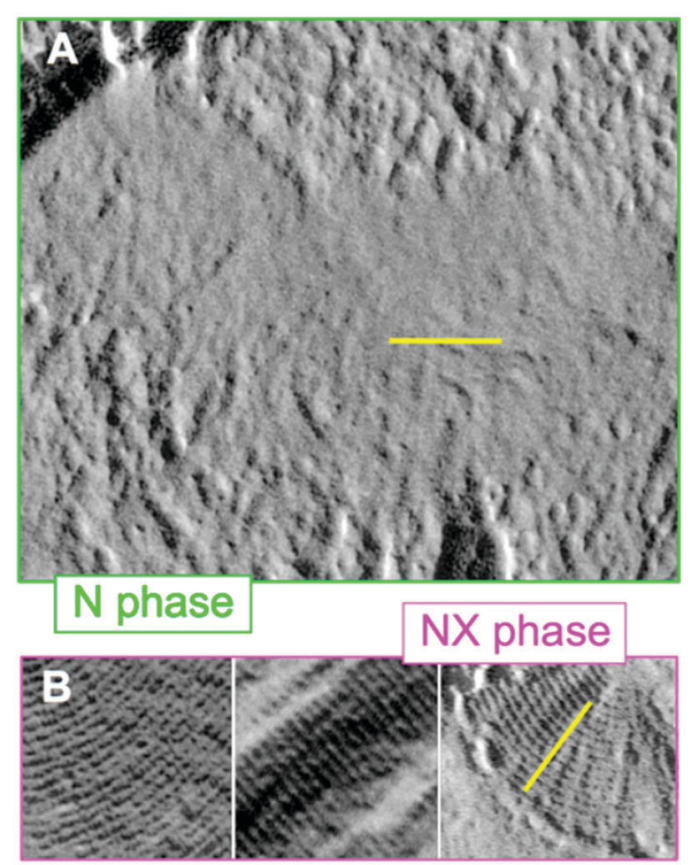

Fig. 2 Comparison of the FFTEM image of $C B 7 C B$ in the nematic phase quenched at $105^{\circ} \mathrm{C}(\mathrm{A})$ and the $\mathrm{N}_{\text {TB }}$ phase quenched at $95^{\circ} \mathrm{C}$ (B). The scale bar corresponds to $100 \mathrm{~nm}$. Reproduced from ref. 48, used with permission of the National Academy of Sciences of the United States of America, copyright 2013.
Table 1 Transition temperatures $\left({ }^{\circ} \mathrm{C}\right)$ for the $\mathrm{CBnCB}$ series ${ }^{17,56,64-66}$

\begin{tabular}{|c|c|c|c|c|c|c|c|c|c|}
\hline No & Name & $n$ & $\mathrm{Cr}$ & & $\mathrm{N}_{\mathrm{TB}}$ & & $\mathrm{N}$ & & Iso \\
\hline 1 & CB6CB & 6 & $\bullet$ & 183 & - & - & $\bullet$ & 230 & $\bullet$ \\
\hline 2 & CB7CB & 7 & $\bullet$ & 102 & $\bullet$ & 104.5 & $\bullet$ & 116 & $\bullet$ \\
\hline 3 & CB8CB & 8 & $\bullet$ & 175.0 & - & - & $\bullet$ & 195.9 & $\bullet$ \\
\hline 4 & CB9CB & 9 & $\bullet$ & 83.0 & $\bullet$ & 105 & $\bullet$ & 119.8 & $\bullet$ \\
\hline 5 & CB10CB & 10 & $\bullet$ & & - & - & $\bullet$ & 174.1 & $\bullet$ \\
\hline 6 & CB11CB & 11 & $\bullet$ & 99.9 & • & 108.6 & $\bullet$ & 125.5 & $\bullet$ \\
\hline
\end{tabular}

The conical angle has been determined for CB7CB (2, Table 2) using birefringence measurements, ${ }^{52}{ }^{2} \mathrm{H}$ NMR spectroscopy on CB7CB- $\mathrm{d}_{4},{ }^{129} \mathrm{Xe}$ NMR on $\mathrm{CB} 7 \mathrm{CB}$ saturated with xenon and $\mathrm{CB} 7 \mathrm{CB}$ doped with $8 \mathrm{CB}-\mathrm{d}_{2}$ as a spin probe. ${ }^{53}$ As the conical angle remains less than the magic angle the $\mathrm{N}_{\mathrm{TB}}$ phase is optically uniaxial with positive birefringence; this has also been demonstrated by connoscopy. ${ }^{54}$ The orientational order parameters $\left\langle P_{2}\right\rangle$ and $\left\langle P_{4}\right\rangle$ for the $\mathrm{CB} n \mathrm{CB}$ series (where $n$ is 7, 8, 9 or 11, see Table 1), as determined by polarised Raman spectroscopy (PRS), ${ }^{55}$ are significantly higher for the dimer CB8CB (3), with even spacer parity, than for the odd parity dimers CB7CB, CB9CB and CB11CB (2, 4 and 6 respectively). Values determined by PRS for both odd- and even-parity dimers are in good agreement with those obtained previously by NMR using anthracene- $\mathrm{d}_{10}$ as a spin probe. ${ }^{56}$ Measurement of the dielectric permittivities of materials exhibiting the twist-bend nematic can provide values of the elastic constants, the conical 'tilt' angle in the $\mathrm{N}_{\mathrm{TB}}$ phase and in some cases order parameter data for both pure compounds and mixtures. ${ }^{57-61}$ Studies on the rheology of the twistbend nematic phase of KA (0.2), a six component mixture of odd-parity bimesogens for which a pitch length of $10.5 \mathrm{~nm}$ was determined by FFTEM, ${ }^{58,62}$ reveal that the $\mathrm{N}_{\mathrm{TB}}$ phase is strongly shear thinning. At low shear stress $(<1 \mathrm{~Pa})$ the viscosity of the $\mathrm{N}_{\mathrm{TB}}$ phase was found to be 1000 times larger than that of the nematic phase in the same material, however, at higher shear stress $(>10 \mathrm{~Pa})$ the viscosity drops two orders of magnitude as the heliconical axis reorients due to shear-induced alignment. $^{63}$

Although supported by a significant body of experimental evidence this view of the local structure has also been disputed, with some experimental evidence interpreted to be counter the heliconical model. Specifically a ${ }^{2} \mathrm{H}$ NMR experiment was interpreted as showing that a helix is not present in the $\mathrm{N}_{\mathrm{TB}} / \mathrm{N}_{\mathrm{X}}$ phase. ${ }^{67}$ Similar periodic length scales exist in the solid state of CB9CB (4) as those measured by FFTEM, with suggestions that the measured pitch may be due to surface freezing. ${ }^{68}$ In the model proposed by Dozov ${ }^{16}$ the spontaneous twit-bend deformation of the nematic director is a consequence of the bend elastic constant $K_{33}$ falling below zero, conversely, experimental studies have shown that this is not the case for $\mathrm{CB} 7 \mathrm{CB} .{ }^{69}$ Most recently, the observation of direct isotropic liquid to $\mathrm{N}_{\mathrm{TB}}$ phases has provided a further challenge to future theoretical treatments. $^{70,71}$ Presently, it seems that experimental evidence 
supports the heliconical model as the best descriptor of the local structure of the twist-bend mesophase.

Deuterium NMR spectroscopy is a powerful tool for the study of the $\mathrm{N}_{\mathrm{TB}}$ phase; the use of a suitably deuterated prochiral mesogen or solute as a spin probe (e.g. anthracene- $\left.\mathrm{d}_{10},{ }^{56} 8 \mathrm{CB}-\mathrm{d}_{2}{ }^{72}\right)$ allows the rapid distinction between the uniaxial nematic and the heliconical twist-bend nematic phases as follows. In the isotropic liquid the deuterium NMR spectrum of a pro-chiral methylene $\left(-\mathrm{CD}_{2}{ }^{-}\right)$is a singlet, in a uniaxial nematic phase the same deuterium environment is a quadrupolar doublet, however, as a consequence of the local chirality results the twist-bend nematic phase these two deuterons are no longer equivalent and so two quadrupolar doublets are observed. Example spectra are given in Fig. 3.

The optical textures of the twist-bend nematic phase are both distinctive and sufficiently different from other mesophases that they can be used for preliminary assignment. Typical optical textures obtained for the $\mathrm{N}_{\mathrm{TB}}$ phase on cooling from the schlieren texture of the nematic phase are presented in Fig. 4; immediately below the phase transition the birefringent regions of what was the schlieren texture in the nematic become blocky, further cooling yields significant changes in the birefringence. More detailed discussion of the optical textures of the $\mathrm{N}_{\mathrm{TB}}$ phase can be found elsewhere. ${ }^{66,73}$ The ability to draw freestanding films of the twist-bend nematic indicates that this mesophase has structural periodicity (Fig. 5). ${ }^{66}$

Calorimetric studies of the nematic to twist-bend nematic phase transition reveal it to be weakly first order and close to tricritical. ${ }^{17,59,60,66,74}$ In non-resonant small angle X-ray scattering experiments the pattern obtained for the twist-bend nematic phase is similar to that of the nematic phase; only diffuse scattering in both the wide and small angle regions as both the
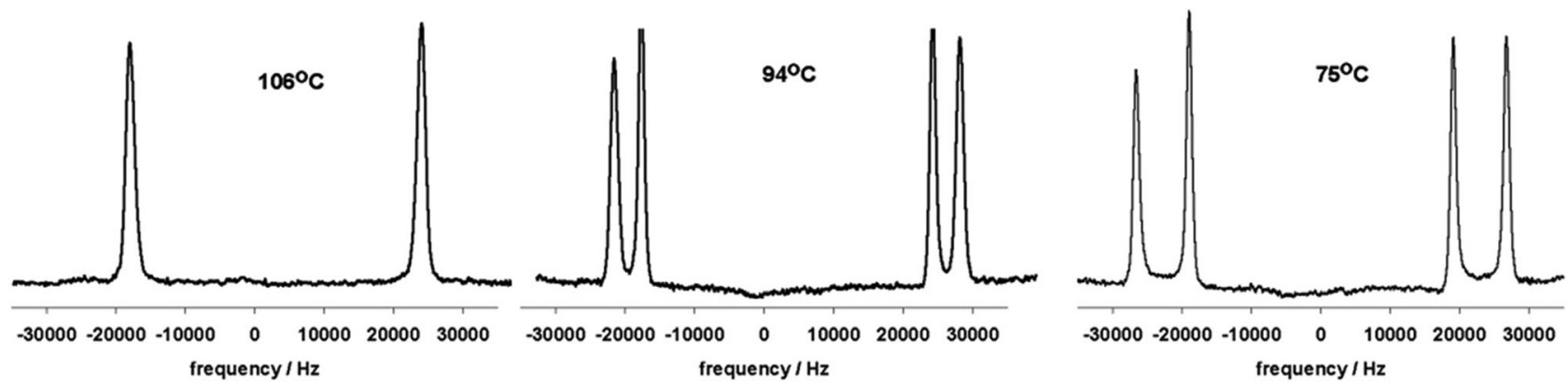

Fig. $3{ }^{2} \mathrm{H}$ NMR spectra of $8 \mathrm{CB}-d_{2}$ dissolved in $\mathrm{CB} 7 \mathrm{CB}$ and recorded in the nematic $\left(106{ }^{\circ} \mathrm{C}, 46.0 \mathrm{MHz}\right)$ and twist-bend nematic $\left(94{ }^{\circ} \mathrm{C}\right.$ and $75{ }^{\circ} \mathrm{C}$, 61.4 MHz). Adapted with permission from ref. 72. Copyright American Chemical Society 2012.
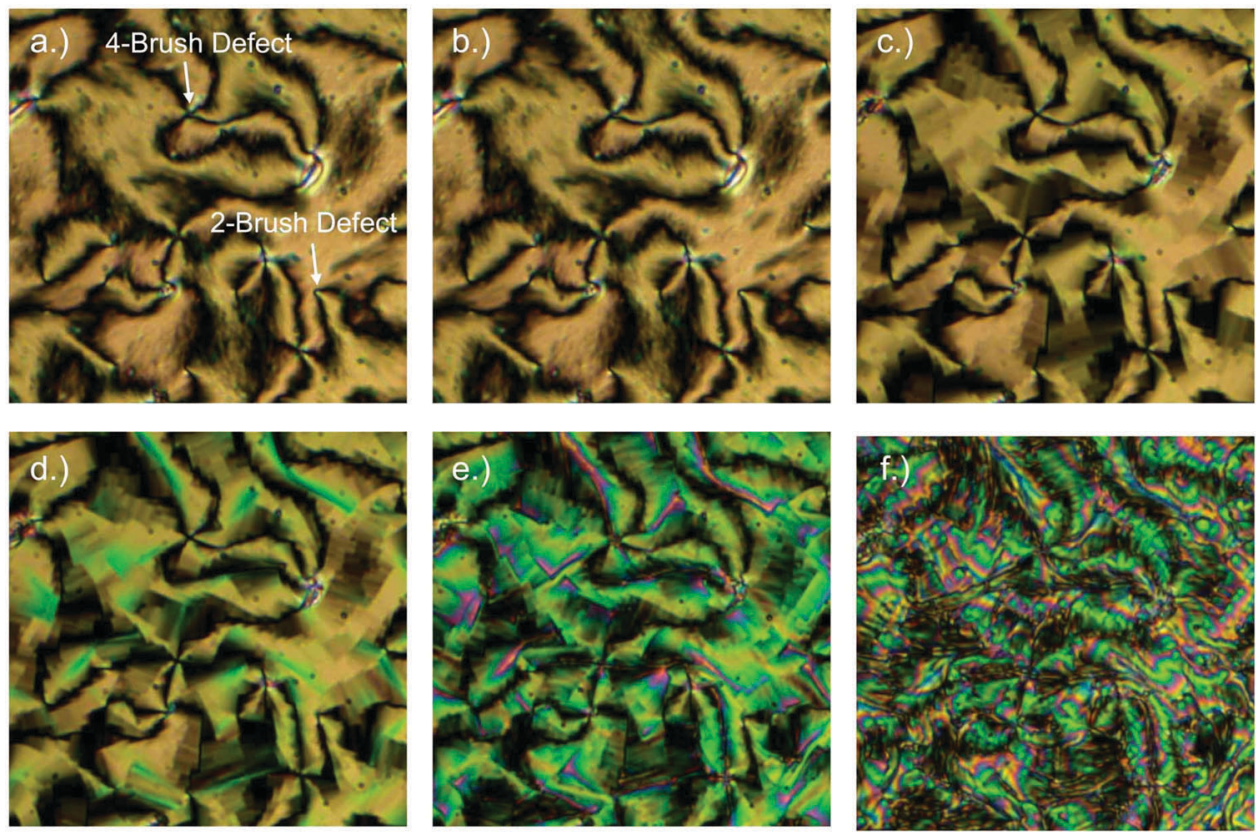

Fig. 4 Polarized optical micrographs of $\mathrm{CB} 11 \mathrm{CB}$ showing the textures observed for (a) the nematic phase at $107^{\circ} \mathrm{C}$; (b) the nematic phase at $106.8^{\circ} \mathrm{C}$; (c) the nematic to $\mathrm{N}_{\mathrm{TB}}$ transition at $106.5^{\circ} \mathrm{C}$; (d) the $\mathrm{N}_{\mathrm{TB}}$ phase at $106.2^{\circ} \mathrm{C}$; (e) the $\mathrm{N}_{\mathrm{TB}}$ phase at $105^{\circ} \mathrm{C}$ and; (f) the $\mathrm{N}_{\text {TB }}$ phase at $100.7^{\circ} \mathrm{C}$. The textures were obtained for a specimen contained in a $9 \mu \mathrm{m}$ cell treated to give homeotropic alignment. Reproduced from ref. 66 with permission of the Royal Society of Chemistry. 


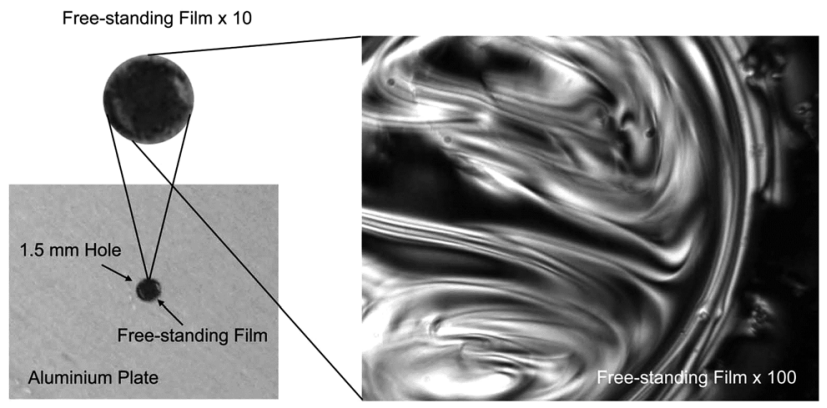

Fig. 5 Photomicrograph of a free standing film of CB11CB drawn over a $1.5 \mathrm{~mm}$ aperture in an aluminium plate, with an exposure time of 500 milliseconds. Reproduced from ref. 66 with permission of the Royal Society of Chemistry.

$\mathrm{N}$ and $\mathrm{N}_{\mathrm{TB}}$ phases lack electron density modulation, despite the spatial periodicity present in the latter. ${ }^{17,19,48,49,75-81}$ SAXS patterns obtained for $\mathrm{CB} 11 \mathrm{CB}(6)$ with $\mathrm{Cu} \mathrm{K} \alpha$ radiation $(\lambda=0.154 \mathrm{~nm})$ for a magnetically aligned (field of $\approx 0.6 \mathrm{~T}$ at sample position) sample in the nematic $\left(110{ }^{\circ} \mathrm{C}\right)$ and the twistbend nematic $\left(99^{\circ} \mathrm{C}\right)$ are given in Fig. 6, using an experimental setup that has been described previously. ${ }^{76}$ Although non-resonant SAXS experiments are not diagnostic for the local structure of the twist-bend nematic phase, they are a useful tool for distinguishing between the $\mathrm{N}_{\mathrm{TB}}$ and smectic phases, in which diffuse layers of spacing $d_{\mathrm{L}}$ lead to sharp scattering at $Q \sim \frac{2 \pi}{d_{\mathrm{L}}}$. As noted by Zhu et al., non-resonant SAXS experiments should be able to distinguish between the twist-bend and splay-bend nematic phases. ${ }^{50}$ For materials suspected of exhibiting a twist-bend nematic phase the construction of phase diagrams with twistbend nematic materials (such as the $\mathrm{CB} n \mathrm{CB}$ compounds) has proved to be a useful way of demonstrating unequivocally that novel materials exhibit this state of matter. ${ }^{17,44,59,76,81-84}$

The potential for stimuli-responsive behaviour in twistbend nematic materials, as well as other LC phases with helical structures, has the potential to yield novel display technologies utilising switchable reflection, ${ }^{85-87}$ as well as in producing defined nanostructures that can be used for photonic applications. ${ }^{88-90}$
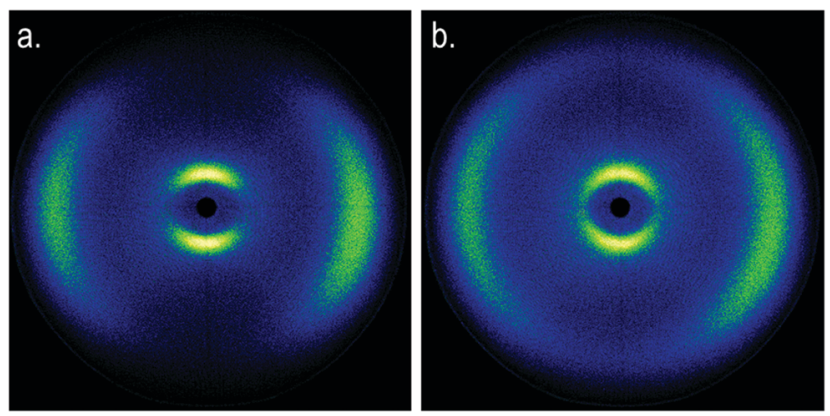

Fig. 6 Two-dimensional small-angle $X$-ray scattering patterns obtained for a magnetically aligned sample of CB11CB (6) in the nematic phase at $110{ }^{\circ} \mathrm{C}(\mathrm{a})$ and the $\mathrm{N}_{\text {TB }}$ phase at $99{ }^{\circ} \mathrm{C}$ (b). The synthesis of CB11CB (6) and the experimental setup used is described in ref. 66 and 76.

\section{Molecular structure and the $\mathrm{N}_{\mathrm{TB}}$ phase}

As with all mesophases the occurrence of the twist-bend nematic phase in a bulk material has its origin in molecular structure, and since the identification of the lower temperature nematic phase exhibited by CB7CB (2) by Cestari et al. as the twist-bend nematic phase there has been a resurgence of interest in the structure property relationships of liquidcrystalline dimers. ${ }^{17}$ We can subdivide the structure of a liquid crystal dimer into sub sections (Fig. 7) as follows. Firstly, there are two mesogenic units that are comprised of rigid, cyclic ring structures (such as phenyl, hetroaryl, cyclohexyl, bicyclooctyl) and these may or may not contain either lateral substituents and/or ring-to-ring link groups such as esters, ${ }^{83}$ imines,,${ }^{91,92}$ azo groups ${ }^{54,93}$ and such. In terms of the choice of terminal group there are examples of polar, ${ }^{83}$ apolar $^{76}$ and mixed polar/apolar units being employed. ${ }^{94,95}$ The mesogenic units are attached to a spacer which, in the context of the $\mathrm{N}_{\mathrm{TB}}$ phase, is almost always a hydrocarbon of odd parity. The chemical nature of the linking group between the mesogenic units and the spacer is also important, with methylene linking groups being dominant but a large and significant number of imine, ${ }^{91,92}$ ether, ${ }^{79,82}$ ester $^{54,96}$ (and combinations thereof) being known. Lastly, the $\mathrm{N}_{\mathrm{TB}}$ phase is known to exist in trimers ${ }^{49,97}$ and tetramers, ${ }^{77}$ and although no such reports have been made to date, it seems highly probable that this phase will also be observed in higher oligomers.

A 'bent' molecular shape is a prerequisite for a material to exhibit the twist-bend nematic phase and this is most commonly achieved by using a spacer of odd parity, although as will be discussed, exceptions exist to this rule where even parity spacers are used and the molecular bend is provided by some other structural unit. When the spacer parity is odd then the material is bent; conversely an even spacer parity affords a near linear material and thus for simple dimers there is a strong even effect due to the significantly different shape; this is well

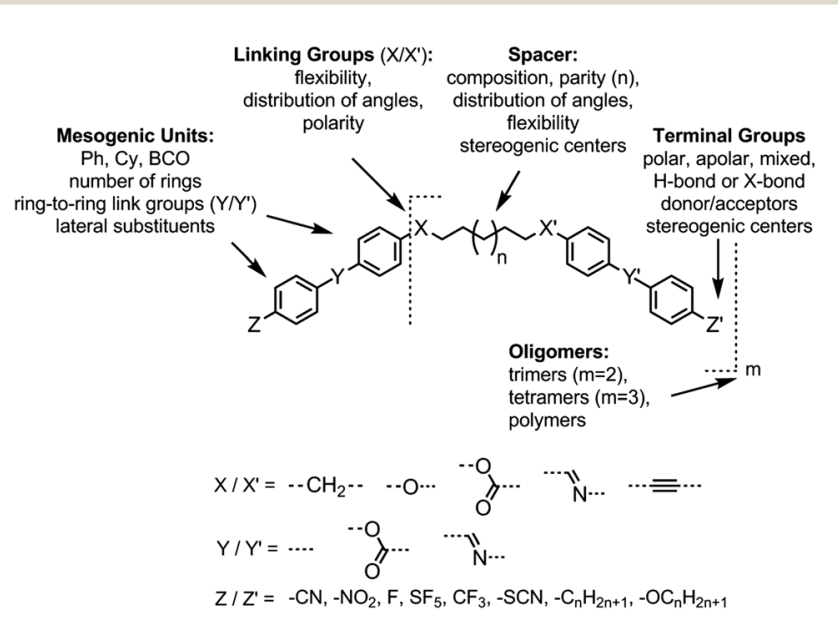

Fig. 7 General structure of materials that exhibit the twist-bend nematic phase and possible variations to molecular structure leading from simple bimesogens to more complex oligomeric structures. 
illustrated by comparison of the properties of the $\mathrm{CB} n \mathrm{CB}$ series of materials (1-6, Table 1). Replacement of both of the methylene linking groups with esters and ethers leads to loss of the $\mathrm{N}_{\text {тв }}$ phase, however the resulting materials still exhibit the nematic phase. ${ }^{81,98}$

\subsection{Methylene linked dimers}

Dimers containing two $4^{\prime \prime}$-alkyl-2' ${ }^{\prime} 3^{\prime}$-difluoroterphenyl mesogenic units joined by either a heptamethylene or undecamethylene spacer were also found to exhibit the twist-bend nematic phase (Table 2), with 7 being one of only a handful of materials exhibiting a twist-bend to smectic phase transition. ${ }^{99}$ Compound 8 was found to exhibit a linear (polar) microsecond optical response to applied electric fields, with domains of opposite handedness exhibiting opposite responses when confined in planar cells. One possible interpretation of this phenomenon was noted by the authors as being a 'very short helical pitch'. ${ }^{84}$

As depicted in Fig. 7 it is possible to include ring-to-ring linking units in the mesogenic units, resulting in predictable changes to the shape and polarity of the resulting material. Concerning the $N$-phenylbenzimine dimers reported by Henderson et al. (Table 3), materials with terminal cyano, methoxy or ethoxy groups and a central pentamethylene spacer (10-12) exhibit nematic and $\mathrm{N}_{\mathrm{TB}}$ phases (identified as $\mathrm{Sm}$ in ref. 101). ${ }^{102}$ In a similar vein to the $\mathrm{CB} n \mathrm{CB}$ compounds, analogous dimers with even spacer parity (13-14) are solely nematogenic and exhibit large increases in clearing point relative to the odd parity materials. ${ }^{101}$

As with the $\mathrm{CB} n \mathrm{CB}$ series of materials the even-parity members of the PCB $n$ PCB series $(\mathbf{1 6}, \mathbf{1 8}$; Table 4) were found to have significantly higher melting and clearing points than the odd-parity materials $(\mathbf{1 5}, \mathbf{1 7}, \mathbf{1 9}$, Table 4$)$. However, whereas the odd-parity materials exhibit the twist-bend nematic phase

Table 2 Transition temperatures $\left({ }^{\circ} \mathrm{C}\right)$ for methylene linked, alkyl terminated $2^{\prime}, 3^{\prime}$-difluoroterphenyl dimers. ${ }^{75,84,100}$ Monotropic phase transitions are presented in parenthesis

\begin{tabular}{|c|c|c|c|c|c|c|c|c|c|c|c|c|}
\hline No & Name & $n$ & $m$ & $\mathrm{Cr}$ & & $\mathrm{Sm}_{\mathrm{X}}$ & & $\mathrm{N}_{\mathrm{TB}}$ & & $\mathrm{N}$ & & Iso \\
\hline 7 & $\mathrm{n} / \mathrm{a}$ & 5 & 7 & $\bullet$ & 101 & $(\bullet$ & $75.4)$ & • & 128.7 & & 157.5 & $\bullet$ \\
\hline 8 & 'M2' & 3 & 11 & - & 94 & - & - & - & 124.9 & - & 180.0 & - \\
\hline 9 & 'M3' & 5 & 11 & - & 85 & - & - & - & 123.0 & • & 170.0 & - \\
\hline
\end{tabular}

Table 3 Transition temperatures $\left({ }^{\circ} \mathrm{C}\right)$ of the $N$-phenylbenzimine dimers $\left(\mathbf{1 0 - 1 4 )}{ }^{101,102}\right.$ Monotropic phase transitions are presented in parenthesis

\begin{tabular}{llllllllllll}
\hline $\mathrm{No}$ & $\mathrm{Name}$ & $\mathrm{R}$ & $\mathrm{N}$ & $\mathrm{Cr}$ & & $\mathrm{N}_{\mathrm{TB}}$ & & $\mathrm{N}$ & & Iso \\
\hline $\mathbf{1 0}$ & $\mathrm{CN} 5 \mathrm{CN}$ & $-\mathrm{CN}$ & 5 & $\bullet$ & 147 & $(\bullet$ & 113 & $\bullet$ & $125)$ & $\bullet$ \\
$\mathbf{1 1}$ & $1 \mathrm{O}-5-\mathrm{O} 1$ & $-\mathrm{OCH}_{3}$ & 5 & $\bullet$ & 123 & $(\bullet$ & 83 & $\bullet$ & $86)$ & $\bullet$ \\
$\mathbf{1 2}$ & $2 \mathrm{O}-5-\mathrm{O} 2$ & $-\mathrm{OC}_{2} \mathrm{H}_{5}$ & 5 & $\bullet$ & 130 & $(\bullet$ & 106 & $\bullet$ & $107)$ & $\bullet$ \\
$\mathbf{1 3}$ & $1 \mathrm{O}-6-\mathrm{O} 1$ & $-\mathrm{OCH}_{3}$ & 6 & $\bullet$ & 140 & - & - & $\bullet$ & 214 & $\bullet$ \\
$\mathbf{1 4}$ & $2 \mathrm{O}-6-\mathrm{O} 2$ & $-\mathrm{OC}_{2} \mathrm{H}_{5}$ & 6 & $\bullet$ & 134 & - & - & $\bullet$ & 223 & $\bullet$
\end{tabular}

Table 4 Transition temperatures $\left({ }^{\circ} \mathrm{C}\right)$ for the $\mathrm{PCBnPCB}$ series. ${ }^{83}$ Monotropic phase transitions are presented in parenthesis

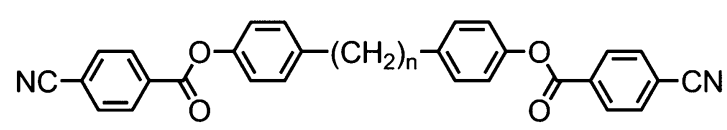

\begin{tabular}{llrlllllll}
\hline No & Name & N & Cr & & $\mathrm{N}_{\text {TB }}$ & & N & & Iso \\
\hline $\mathbf{1 5}$ & PCB7PCB & 7 & $\bullet$ & 149.0 & $(\bullet$ & 120.0 & $\bullet$ & $139.0)$ & $\bullet$ \\
$\mathbf{1 6}$ & PCB8PCB & 8 & $\bullet$ & 195.3 & - & - & $\bullet$ & 212.4 & $\bullet$ \\
$\mathbf{1 7}$ & PCB9PCB & 9 & $\bullet$ & 157.6 & $(\bullet$ & 114.5 & $\bullet$ & $146.6)$ & $\bullet$ \\
$\mathbf{1 8}$ & PCB10PCB & 10 & $\bullet$ & 193.4 & - & - & $\bullet$ & $187.2)$ & $\bullet$ \\
$\mathbf{1 9}$ & PCB11PCB & 11 & $\bullet$ & 157.6 & $(\bullet$ & 113.9 & $\bullet$ & $143.8)$ & $\bullet$
\end{tabular}

the even-parity homologues lack the perquisite bent shape and thus do not exhibit this phase. Additionally the even-parity materials, as a consequence of their anticipated liner shape, have significantly higher melting and clearing points than the oddparity materials. The identity of the $\mathrm{N}_{\mathrm{TB}}$ phase of compounds $\mathbf{1 5}$, 17 and 19 was confirmed by miscibility with CB11CB. ${ }^{83}$

Reversal of the ester linking units of $\mathbf{1 7}$ affords compound 20 (Table 5), which has marginally reduced $\mathrm{N}_{\mathrm{TB}}-\mathrm{N}$ and N-Iso transition temperatures. The positioning of a lateral fluoro group in either the 2- or 3-positions of the outermost ring leads to reduced clearing points and $\mathrm{N}-\mathrm{N}_{\mathrm{TB}}$ transition temperatures (in the case of $\mathbf{2 1}$ it occurs simultaneously with crystallisation at around $75{ }^{\circ} \mathrm{C}$ ). The use of a 'three-ring' mesogenic unit (23) as opposed to a two ring unit (7) leads to significant increases to the $\mathrm{N}_{\mathrm{TB}}-\mathrm{N}$ transition temperature as well as a $180^{\circ} \mathrm{C}$ increase in the clearing point; this indicates that the aspect ratio of the mesogenic units (i.e. length to breadth ratio) of the dimer can significantly change the thermal behaviour of the material, as was demonstrated with compounds $\mathbf{1 7}$ and 20.

Table 5 Transition temperatures $\left({ }^{\circ} \mathrm{C}\right)$ of nonamethylene linked dimers with varied mesogenic unit composition. ${ }^{83}$ Monotropic phase transitions are presented in parenthesis

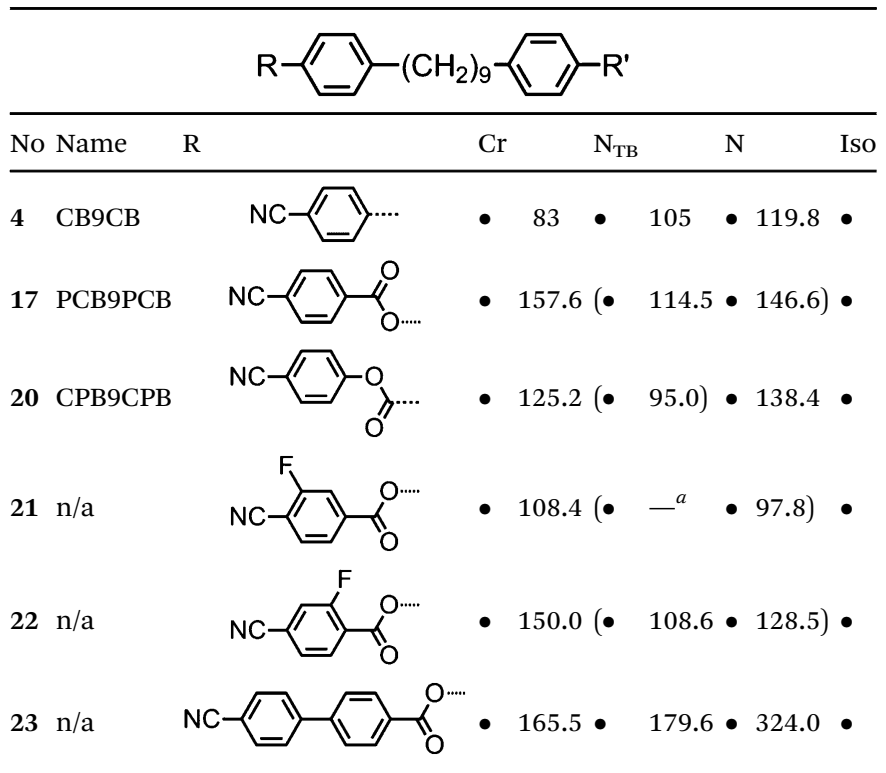

${ }^{a}$ The $\mathrm{N}_{\mathrm{TB}}$ phase could be observed with rapid uncontrolled cooling, however this precludes accurate determination of the transition temperature. 
Table 6 Transition temperatures $\left({ }^{\circ} \mathrm{C}\right)$ of methylene linked dimers with various polar terminal groups. ${ }^{83}$ Monotropic phase transitions are presented in parenthesis

\begin{tabular}{|c|c|c|c|c|c|c|c|c|c|}
\hline No. & $\mathrm{Y}$ & $n$ & $\mathrm{Cr}$ & & $\mathrm{N}_{\mathrm{TB}}$ & & $\mathrm{N}$ & & I \\
\hline 15 & $\mathrm{CN}$ & 5 & • & 149 & $(\bullet$ & 120.0 & $\bullet$ & 139.0) & - \\
\hline 17 & $\mathrm{CN}$ & 7 & • & 157.6 & (• & 114.5 & $\bullet$ & 146.6) & - \\
\hline 24 & $\mathrm{~F}$ & 5 & - & 91.5 & - & - & - & - & - \\
\hline 25 & $\mathrm{~F}$ & 7 & $\bullet$ & 97.6 & - & - & - & - & - \\
\hline 26 & $\mathrm{CF}_{3}$ & 5 & $\bullet$ & 114.9 & - & - & - & - & - \\
\hline 27 & $\mathrm{CF}_{3}$ & 7 & • & 102.4 & - & - & - & - & $\bullet$ \\
\hline 28 & SCN & 5 & - & 105.1 & $(\bullet$ & 103.3) & $\bullet$ & 120.5 & • \\
\hline 29 & SCN & 7 & $\bullet$ & 97.7 & • & 103.7 & $\bullet$ & 127.4 & • \\
\hline 30 & $\mathrm{NO}_{2}$ & 5 & $\bullet$ & 113.3 & - & - & - & - & - \\
\hline 31 & $\mathrm{NO}_{2}$ & 7 & - & 105.4 & - & - & $(\bullet$ & 97.8) & • \\
\hline 32 & $\mathrm{SF}_{5}$ & 5 & $\bullet$ & 126.5 & - & - & - & - & • \\
\hline 33 & $\mathrm{SF}_{5}$ & 7 & • & 123.0 & - & - & - & - & • \\
\hline
\end{tabular}

The effect of polar terminal groups on the $\mathrm{N}_{\mathrm{TB}}$ was also explored by Goodby et al., who synthesised a number of methylene-linked dimers consisting of a heptamethylene or nonamethylene spacer, two phenyl benzoate mesogenic units and one of six polar terminal groups; cyano $(7,9)$, fluoro $(\mathbf{2 4}, \mathbf{2 5})$, trifluoromethyl $(\mathbf{2 6}, \mathbf{2 7})$, isothiocyanate $(\mathbf{2 8}, \mathbf{2 9})$, nitro $(30,31)$ and pentafluorosulfanyl $(32,33)$. Many of these materials were non mesogenic (see Table 6), although the compounds featuring $\mathrm{CN}$ and SCN terminal groups exhibited both nematic and $\mathrm{N}_{\mathrm{TB}}$ phases. Comparing the compounds in Tables 5 and 6 it was noted that the neither the incidence nor thermal stability of the twist-bend nematic phase depends on the dipole moment. ${ }^{45}$

In unsymmetrical liquid-crystalline bimesogens with varying polar terminal units it was found that functional groups that are normally detrimental to mesophase stability (such as $\mathrm{CF}_{3}, \mathrm{SF}_{5}$ ) could be incorporated into the molecular structure, with the resulting material still retaining the nematic and twistbend phases (Table 7). When studied by SAXS no significant differences in the obtained patterns were observed between the symmetrical material 7 and unsymmetrical compounds such as 35, with the diffuse small-angle scattering peak being approximately one half of the all trans molecular length and therefore indicating that the two distinct polar groups are not segregated in either the nematic or nematic twist-bend phases.

Ahmed et al. reported several unsymmetrical bimesogens (Table 8), several of which were found to exhibit the twist-bend nematic phase. Ahmed et al. suggested that the position of polar groups (i.e. lateral, terminal or absent) is not critical for the formation of the $\mathrm{N}_{\mathrm{TB}}$ phase, as was also suggested earlier. ${ }^{45}$ As shown in Table 8, there is a marked increase in clearing points with increasing aspect ratio, whilst reducing the symmetry of the molecule was found to lead to lower melting points. The replacement of a single phenyl ring in CB9CB with thiophene (to afford 39) leads to a small drop in both the clearing point and $\mathrm{N}-\mathrm{N}_{\mathrm{TB}}$ transition temperature, presumably
Table 7 The transition temperatures $\left({ }^{\circ} \mathrm{C}\right)$ of unsymmetrical bimesogens possessing various polar terminal units. Transitions in parenthesis are monotropic, i.e. they occur below the melting point of the material ${ }^{95}$

\begin{tabular}{lllrllllll} 
& & & & & & & \\
\hline No. & $\mathrm{X}$ & $\mathrm{Cr}$ & & $\mathrm{N}_{\mathrm{TB}}$ & & $\mathrm{N}$ & & Iso \\
\hline 7 & $-\mathrm{CN}$ & $\bullet$ & 157.6 & $(\bullet$ & 114.5 & $\bullet$ & $146.6)$ & $\bullet$ \\
34 & $-\mathrm{SCN}$ & $\bullet$ & 95.6 & $\bullet$ & 100.0 & $\bullet$ & 123.8 & $\bullet$ \\
35 & $-\mathrm{NO}_{2}$ & $\bullet$ & 115.4 & $(\bullet$ & $100.5)$ & $\bullet$ & 124.9 & $\bullet$ \\
36 & $-\mathrm{F}_{3}$ & $\bullet$ & 86.2 & $(\bullet$ & $78.2)$ & $\bullet$ & 95.9 & $\bullet$ \\
37 & $-\mathrm{CF}_{3}$ & $\bullet$ & 110.0 & $(\bullet$ & 69.6 & $\bullet$ & $78.3)$ & $\bullet$ \\
38 & $-\mathrm{SF}_{5}$ & $\bullet$ & 102.2 & $(\bullet$ & 61.1 & $\bullet$ & $72.8)$ & $\bullet$
\end{tabular}

due to the non-linearity of a 2,5-disubstitued thiophene unit. Compound 46 exhibits a transition from the $\mathrm{N}_{\mathrm{TB}}$ phase into an as yet unidentified, highly ordered smectic $\left(\mathrm{Sm}_{\mathrm{X}}\right)$ mesophase.

In 'polar' dimers and bimesogens, i.e. materials exhibiting well-defined polar terminal or lateral substituents (such as cyano, nitro, fluoro groups etc.), the $\mathrm{N}_{\mathrm{TB}}$ phase does not appear to exhibit any dependency on the molecular dipole moment. ${ }^{83,94,103,104}$ For unrelated materials with similar clearing points the $\mathrm{N}-\mathrm{N}_{\mathrm{TB}}$ transition temperatures are, apparently, almost identical; for example compounds 22 and 29, 45 and 46.

Moving now to materials lacking polar functional groups in either the terminal or lateral positions of the mesogenic units, the nonamethylene linked phenyl 4-pentylbenzoate dimer 47 was found to exhibit both nematic and twist-bend nematic mesophases, although both were monotropic. Replacement of the outermost phenyl ring of 47 (Table 9) with trans cyclohexyl affords a small increase in melting point and a large increase in clearing point, however the $\mathrm{N}_{\mathrm{TB}}$ phase is lost. Replacement of the phenyl ring with $[2,2,2]$ bicyclooctane (BCO, 49) again affords an increase in clearing point, analogous to the behaviour of calamitic materials, ${ }^{105}$ however in this case the material still exhibits the $\mathrm{N}_{\mathrm{TB}}$ phase with an accompanying increase in thermal stability of over $30^{\circ} \mathrm{C}$.

Turning now to analogues of $\mathbf{4 7}$ with varying terminal chain length, the melting points, $\mathrm{N}_{\mathrm{TB}}-\mathrm{N}$ and $\mathrm{N}$-Iso transition temperatures do not show significant variation aside from a small odd-even effect. All phase transitions are monotropic, and in the case of $\mathbf{5 3}$ and $\mathbf{5 5}$ recrystallisation occurs directly from the isotropic liquid due to the short range of supercooling.

Incorporating an alkoxy terminal chain in lieu of an alkyl (Table 11) leads to increased melting points, but also significant increases in the $\mathrm{N}-\mathrm{I}$ and $\mathrm{N}-\mathrm{N}_{\mathrm{TB}}$ transition temperatures to the point where 58, 59 and $\mathbf{6 0}$ exhibit enantiotropic $\mathrm{N}_{\text {Тв }}$ phases. Compound 60 exhibits a transition from the $\mathrm{N}_{\mathrm{TB}}$ phase into an anticlinic smectic C phase - this is the only known example of this phase transition that is currently known. The associated enthalpy, as measured by differential scanning calorimetry, of the $\mathrm{SmC}_{\mathrm{A}}-\mathrm{N}_{\mathrm{TB}}$ transition of $\mathbf{6 0}$ is an order of magnitude larger than the $\mathrm{N}_{\mathrm{TB}}-\mathrm{N}$ phase transition. Study of $\mathbf{6 0}$ by small angle $\mathrm{X}$-ray scattering reveals that at the phase transition the correlation length increases from roughly $5.5 \mathrm{~nm}$ in the $\mathrm{N}_{\text {Tв }}$ phase to $27 \mathrm{~nm}$ in the $\mathrm{SmC}_{\mathrm{A}}$ phase. The $\mathrm{SmC}_{\mathrm{A}}$ phase has an average layer 
Table 8 Transition temperatures $\left({ }^{\circ} \mathrm{C}\right)$ for the nonamethylene linked dimers reported by Ahmed et al. ${ }^{94}$ Monotropic phase transitions are presented in parenthesis

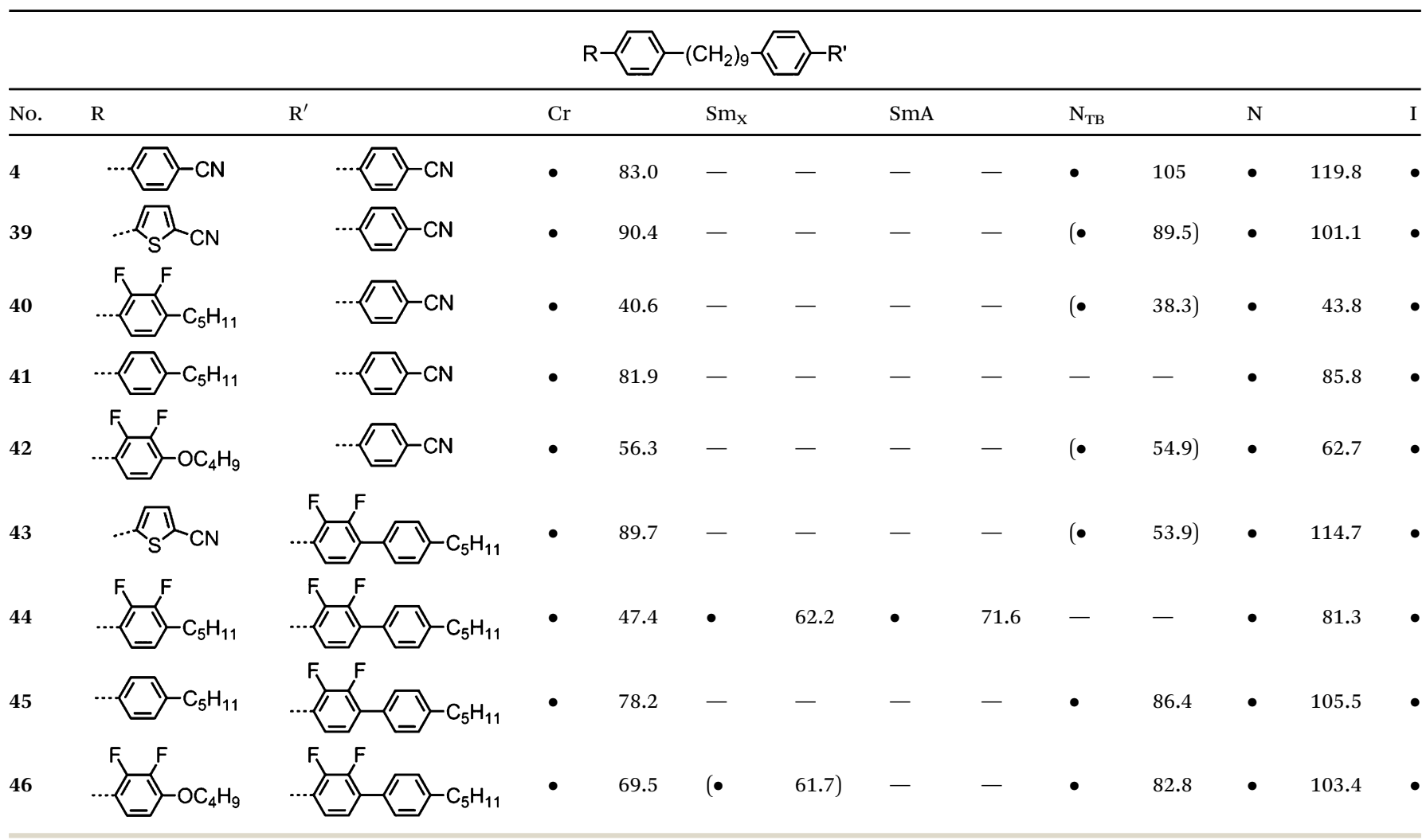

Table 9 Transition temperatures $\left({ }^{\circ} \mathrm{C}\right)$ reported for compounds $\mathbf{4 7 - 4 9 .}{ }^{76}$ Monotropic phase transitions are presented in parenthesis

$$
\text { R- }
$$

\begin{tabular}{lllllllll}
\hline No & $\mathrm{R}$ & & $\mathrm{Cr}$ & & $\mathrm{N}_{\mathrm{TB}}$ & & $\mathrm{N}$ & \\
\hline 47 & $\mathrm{C}_{5} \mathrm{H}_{11}$ & \\
48 & $\mathrm{C}_{5} \mathrm{H}_{11}$
\end{tabular}

spacing equal to 0.5 molecular lengths, and thus is extensively intercalated. The $\mathrm{C}_{7}$ homologue (61) exhibits a nematic to $\mathrm{SmC}_{\mathrm{A}}$ transition, whilst at a terminal chain length of $\mathrm{C}_{8}(\mathbf{6 2})$ or greater neither the nematic nor $\mathrm{N}_{\mathrm{TB}}$ phase are observed, instead a direct isotropic to anticlinic smectic $\mathrm{C}$ transition occurs (Fig. 8).

As was reported for compounds $\mathbf{2 2}$ and $\mathbf{2 3}$ the incorporation of one or two lateral fluoro group in either the 2- or 3-positions of the outermost ring leads to reduced clearing points and $\mathrm{N}-\mathrm{N}_{\mathrm{TB}}$ transition temperatures; in the case of compound 67 the material does not exhibit the twist-bend nematic phase (Table 12). Compound 65 exhibits a direct isotropic to smectic $\mathrm{C}_{\mathrm{A}}$ phase transition, however, incorporating a methyl or methoxy group in the 2-position of the outermost ring (to afford 68 and 69 respectively) disrupts the packing that leads to the $\mathrm{SmC}_{\mathrm{A}}$ phase

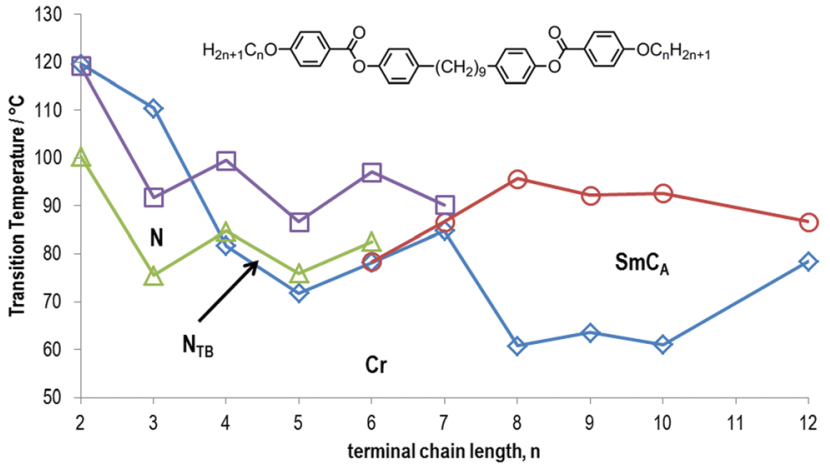

Fig. 8 Plot of transition temperatures $\left({ }^{\circ} \mathrm{C}\right)$ as a function of the length of the terminal alkoxy chain for compounds $56-65 .{ }^{49}$

and the materials instead exhibit nematic and twist-bend nematic mesophases, albeit with significantly $\left(>50{ }^{\circ} \mathrm{C}\right)$ reduced clearing points. The steric footprint of fluorine is much smaller than that of a methyl or methoxy group, and so when it is used as a lateral substituent the depression in clearing point is not as pronounced and the Iso- $\mathrm{SmC}_{\mathrm{A}}$ phase transition is retained.

Increasing the aspect ratio of the phenyl 4-alkylbenzoate dimers (Table 10) to afford the phenyl 4-alkylbiphenyl-4'carboxylate materials (Table 13) leads to significant increases in both clearing and melting points, with shorter homologues (71 and 72) exhibiting nematic and $\mathrm{N}_{\mathrm{TB}}$ mesophases, with longer homologues (73 and 74) exhibit an anticlinic 
Table 10 Transition temperatures $\left({ }^{\circ} \mathrm{C}\right)$ reported for compounds 47 and 50-55. ${ }^{76}$ Monotropic phase transitions are presented in parenthesis

\begin{tabular}{lllllllll}
\hline & & & & & & & \\
\hline $\mathrm{No}$ & $\mathrm{R}$ & $\mathrm{Cr}$ & & $\mathrm{N}_{\mathrm{TB}}$ & & $\mathrm{N}$ & & Iso \\
\hline $\mathbf{5 0}$ & $\mathrm{C}_{2} \mathrm{H}_{5}$ & $\bullet$ & 66.8 & $(\bullet$ & 48.4 & $\bullet$ & $57.2)$ & $\bullet$ \\
$\mathbf{5 1}$ & $\mathrm{C}_{3} \mathrm{H}_{7}$ & $\bullet$ & 77.6 & $(\bullet$ & 59.5 & $\bullet$ & $67.1)$ & $\bullet$ \\
$\mathbf{5 2}$ & $\mathrm{C}_{4} \mathrm{H}_{9}$ & $\bullet$ & 67.3 & $(\bullet$ & 46.2 & $\bullet$ & $51.0)$ & $\bullet$ \\
$\mathbf{4 7}$ & $\mathrm{C}_{5} \mathrm{H}_{11}$ & $\bullet$ & 72.8 & $(\bullet$ & 58.8 & $\bullet$ & $66.2)$ & $\bullet$ \\
$\mathbf{5 3}$ & $\mathrm{C}_{6} \mathrm{H}_{13}$ & $\bullet$ & 74.4 & - & - & - & - & $\bullet$ \\
$\mathbf{5 4}$ & $\mathrm{C}_{7} \mathrm{H}_{15}$ & $\bullet$ & 67.6 & - & - & $(\bullet$ & $61.7)$ & $\bullet$ \\
$\mathbf{5 5}$ & $\mathrm{C}_{8} \mathrm{H}_{17}$ & $\bullet$ & 66.2 & - & - & - & - & $\bullet$
\end{tabular}

smectic C phase. Compound 72, with terminal propyl chains, exhibits a nematic to unknown-smectic mesophase transition, whereas $\mathbf{7 4}$ exhibits an additional monotropic smectic B phase. ${ }^{76,78,106}$

The behaviour of the phenyl 4-alkylbiphenyl-4'-carboxylate materials (Table 13) is largely mirrored by the analogous phenyl trans 4-(4-alkylcycohexyl)benzoate dimers (Table 14), with the ethyl- and propy-terminated materials ( 75 and 76 ) exhibiting both nematic and $\mathrm{N}_{\mathrm{TB}}$ mesophases, and the butyland pentyl-terminated homologues exhibiting nematic and $\mathrm{SmC}_{\mathrm{A}}$ phases (77 and 78 ). However, the trans, trans 4-(4-alkylcycohexyl)cyclohexylcarboxylate dimers (Table 15) differ significantly in terms of their liquid-crystalline behaviour; all materials (79-82) exhibit nematic and smectic B mesophases, with butyl and pentyl terminated derivatives also exhibiting additional smectic phases.

When studied by small-angle X-ray scattering, the various smectic phases of 71-82 were found to be intercalated, that is, the layer spacing is roughly one half of the all trans molecular length regardless of the mesophase. ${ }^{106}$ Comparing the behaviour of 71-82. The $\mathrm{N}_{\text {тв }}$ phase becomes less stable in comparison to intercalated smectic phases (both $\mathrm{SmC}_{\mathrm{A}}$ and $\mathrm{SmB}$ ) as the proportionality of $\sigma$ to $\pi$-bonded structure is increased, mirroring the trends seen for conventional calamitic materials. ${ }^{107}$

Table 11 Transition temperatures $\left({ }^{\circ} \mathrm{C}\right)$ of phenyl 4-alkoxybenzoate dimers with a nonamethylene spacer $56-65 .^{76}$ Monotropic phase transitions are presented in parenthesis

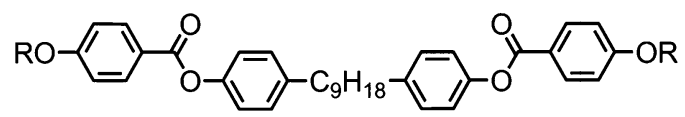

\begin{tabular}{lllrllllllll}
\hline $\mathrm{No}$ & $\mathrm{R}$ & $\mathrm{Cr}$ & \multicolumn{3}{c}{$\mathrm{SmC}_{\mathrm{A}}$} & & $\mathrm{N}_{\mathrm{TB}}$ & & $\mathrm{N}$ & & $\mathrm{Iso}$ \\
\hline $\mathbf{5 6}$ & $\mathrm{C}_{2} \mathrm{H}_{5}$ & $\bullet$ & 119.6 & - & - & $(\bullet$ & 100.4 & $\bullet$ & 119.2 & $\bullet$ \\
$\mathbf{5 7}$ & $\mathrm{C}_{3} \mathrm{H}_{7}$ & $\bullet$ & 110.4 & - & - & $(\bullet$ & 75.5 & $\bullet$ & 91.8 & $\bullet$ \\
$\mathbf{5 8}$ & $\mathrm{C}_{4} \mathrm{H}_{9}$ & $\bullet$ & 83.3 & - & - & $\bullet$ & 84.7 & $\bullet$ & 99.5 & $\bullet$ \\
$\mathbf{5 9}$ & $\mathrm{C}_{5} \mathrm{H}_{11}$ & $\bullet$ & 71.8 & - & - & $\bullet$ & 76.0 & $\bullet$ & 86.6 & $\bullet$ \\
$\mathbf{6 0}$ & $\mathrm{C}_{6} \mathrm{H}_{13}$ & $\bullet$ & 78.2 & $\bullet$ & 78.4 & $\bullet$ & 85.2 & $\bullet$ & 97.1 & $\bullet$ \\
$\mathbf{6 1}$ & $\mathrm{C}_{7} \mathrm{H}_{15}$ & $\bullet$ & 84.8 & $\bullet$ & 86.6 & - & - & $\bullet$ & 90.2 & $\bullet$ \\
$\mathbf{6 2}$ & $\mathrm{C}_{8} \mathrm{H}_{17}$ & $\bullet$ & 60.8 & $\bullet$ & 95.7 & - & - & - & - & $\bullet$ \\
$\mathbf{6 3}$ & $\mathrm{C}_{9} \mathrm{H}_{19}$ & $\bullet$ & 63.5 & $\bullet$ & 92.2 & - & - & - & - & $\bullet$ \\
$\mathbf{6 4}$ & $\mathrm{C}_{10} \mathrm{H}_{21}$ & $\bullet$ & 61.0 & $\bullet$ & 92.6 & - & - & - & - & $\bullet$ \\
$\mathbf{6 5}$ & $\mathrm{C}_{12} \mathrm{H}_{25}$ & $\bullet$ & 78.5 & $\bullet$ & 86.6 & - & - & - & - & $\bullet$
\end{tabular}

Table 12 Transition temperatures $\left({ }^{\circ} \mathrm{C}\right)$ reported for compounds 56 , $65-70 .{ }^{76}$ Monotropic phase transitions are presented in parenthesis

\begin{tabular}{|c|c|c|c|c|c|c|c|c|c|c|c|c|}
\hline No & $n$ & $\mathrm{X}$ & $\mathrm{Y}$ & C & & $\mathrm{SmC}$ & & $\mathrm{N}_{\mathrm{TB}}$ & & $\mathrm{N}$ & & Iso \\
\hline 56 & 2 & $\mathrm{H}$ & $\mathrm{H}$ & - & 119.6 & - & - & $(\bullet$ & 100.4 & • & 119.2 & •) \\
\hline 66 & 2 & $\mathrm{H}$ & $\mathrm{F}$ & - & 102.0 & - & - & $(\bullet$ & 84.5 & • & 101.9) & - \\
\hline 67 & 2 & $\mathrm{~F}$ & $\mathrm{~F}$ & - & 111.4 & - & - & - & - & $(\bullet$ & 97.9) & - \\
\hline 65 & 12 & $\mathrm{H}$ & $\mathrm{H}$ & - & 78.5 & $\bullet$ & 86.6 & - & - & - & - & - \\
\hline 68 & 12 & $\mathrm{H}$ & $\mathrm{CH}_{3}$ & - & 61.5 & - & - & $(\bullet$ & 28.7 & • & 33.3 & •) \\
\hline 69 & 12 & $\mathrm{H}$ & $\mathrm{OCH}_{3}$ & - & 60.3 & - & - & $(\bullet$ & 25.7 & • & 30.8 & •) \\
\hline 70 & 12 & $\mathrm{H}$ & $\mathrm{F}$ & - & 66.7 & • & 76.0 & - & - & & - & $\bullet$ \\
\hline
\end{tabular}

\subsection{Dimers with other linking groups}

3.2.1. Ether-linked dimers. There had been some suggestion initially that perhaps, due to differences in conformation and elastic constants when compared to methylene linked materials, ${ }^{36,102}$ dimers and bimesogens with ether linking groups could not exhibit the $\mathrm{N}_{\mathrm{TB}}$ phase. Certainly the replacement of methylene linking groups with ethers has an impact on the distribution of conformers and elastic constants, ${ }^{108}$ however, the first ether-linked twist-bend materials were reported ${ }^{59,79,82}$ soon after the observation of the twist-bend phase in ad-mixtures of methylene and ether linked bimesogens. ${ }^{62}$

As shown in Table 16, and depending on the parity of the central spacer as well as the terminal chain length, the so-called FBOnODFCB $m$ materials exhibit twist-bend or smectic A mesophases, the latter being identified as the subtype $A_{2}$ by SAXS and the $\mathrm{N}_{\mathrm{TB}}$ phase being identified unequivocally by miscibility studies with $\mathrm{CB} 11 \mathrm{CB} .{ }^{79}$ Compound 85 remains the only example to date of a material exhibiting a twist-bend nematic to smectic A phase transition, with this polymorphism being extremely sensitive to even small changes in molecular structure; any increase or decrease in the length of the terminal chain results in the loss of the $\mathrm{N}_{\mathrm{TB}}$ phase. In all cases, replacement of the 4-fluorobiphenyl mesogenic unit with a 4-cyanobiphenyl and several fluorinated biphenyls was found to suppress the formation of both the ' $\mathrm{X}$ ' and $\mathrm{SmA}_{2}$ phases exhibited by 85 (Table 17). However, in all cases the nematic phase was retained, while all but 90 and 91 still exhibit the $\mathrm{N}_{\mathrm{TB}}$ phase. ${ }^{79,82}$

Sebastián et al. presented a thorough reinvestigation into $\mathbf{9 5}$ (FFO9OCB) and demonstrated that this material exhibits a twist-bend nematic phase, which had not been reported in previous works concerning this material. ${ }^{59,109,110}$ Analysis of the dielectric behaviour of $\mathbf{9 5}$ according to the model of Stocchero et al. ${ }^{111}$ suggests that the molecules are almost entirely $(94 \%$ at $T_{\mathrm{N}-\mathrm{I}}, 98 \%$ at $T_{\mathrm{N}-\mathrm{I}}-45{ }^{\circ} \mathrm{C}$ ) in their all trans conformation. The octamethylene homologue 96 (FFO8OCB) exhibits significantly higher melting and clearing points and does not exhibit the $\mathrm{N}_{\mathrm{TB}}$ phase, ${ }^{112}$ similar behaviour can be seen for even members of the $\mathrm{CB} n \mathrm{CB}$ series. Later, the analogous 97 (FFO11OCB) was also found to exhibit a twist-bend nematic phase ${ }^{79}$ with the transition temperatures being only marginally different to the nonamethylene material initially reported by Sebastián $e t$ al. It is possible, if not 
Table 13 Transition temperatures $\left({ }^{\circ} \mathrm{C}\right)$ of the phenyl biphenylcarboxylate dimers $\mathbf{7 1 - 7 4 . 7 6 , 7 8 , 1 0 6}$ Monotropic phase transitions are presented in parenthesis

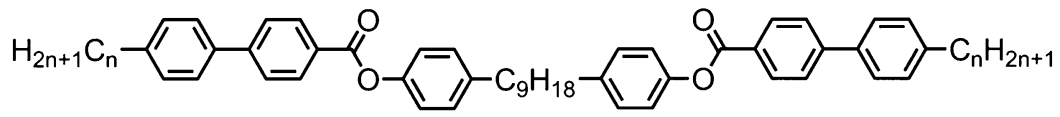

\begin{tabular}{|c|c|c|c|c|c|c|c|c|c|c|c|c|c|c|}
\hline No & $n$ & $\mathrm{Cr}$ & & B & & $\mathrm{SmC}_{\mathrm{A}}$ & & $\mathrm{Sm}$ & & $\mathrm{N}_{\mathrm{TB}}$ & & $\mathrm{N}$ & & Iso \\
\hline 72 & 3 & $\bullet$ & 129.3 & - & - & - & - & - & 137.1 & $\bullet$ & 167.2 & - & 244.9 & - \\
\hline 73 & 3 & • & 117.3 & - & - & • & 172.8 & - & - & - & - & • & 228.1 & - \\
\hline
\end{tabular}

Table 14 Transition temperatures $\left({ }^{\circ} \mathrm{C}\right)$ of the phenyl phenylcyclohexylcarboxylate dimers $\mathbf{7 5 - 7 8}{ }^{76,106}$ Monotropic phase transitions are presented in parenthesis

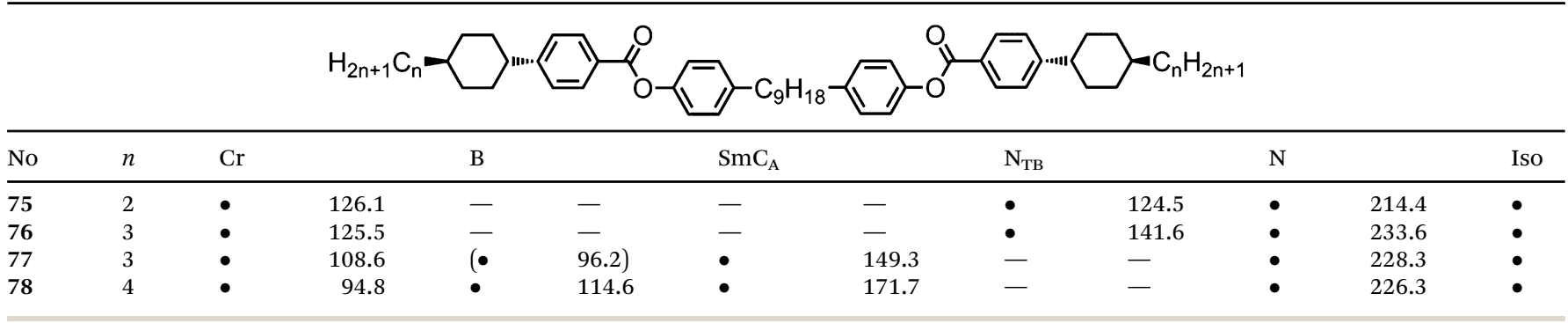

Table 15 Transition temperatures $\left({ }^{\circ} \mathrm{C}\right)$ of the phenyl bicyclohexylcarboxylate dimers $\mathbf{7 9 - 8 2 ^ { 7 6 , 1 0 6 }}$

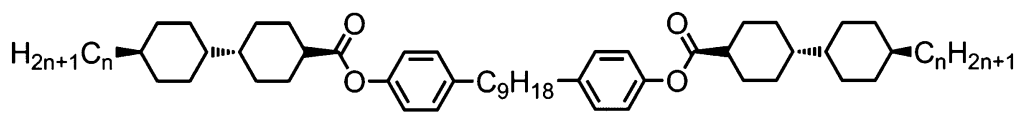

\begin{tabular}{lllllllllll}
\hline No & $n$ & Cr & & B & & SmC & & SmA & & N \\
\hline $\mathbf{7 9}$ & 2 & $\bullet$ & 69.0 & $\bullet$ & 189.2 & - & - & - & - & Iso \\
$\mathbf{8 0}$ & 3 & $\bullet$ & 77.0 & $\bullet$ & 174.3 & - & - & - & - & $\bullet$ \\
$\mathbf{8 1}$ & 3 & $\bullet$ & 82.9 & $\bullet$ & 199.5 & - & - & $\bullet$ & 200.3 & $\bullet$ \\
$\mathbf{8 2}$ & 4 & $\bullet$ & 85.5 & $\bullet$ & 199.1 & $\bullet$ & 202.8 & $\bullet$ & 208.1 & $\bullet$
\end{tabular}

Table 16 Transition temperatures $\left({ }^{\circ} \mathrm{C}\right)$ of compounds 83-88 (FBO$n O D F C B m$ ), illustrating the influence of the parity of the spacer and the terminal chain. ${ }^{79,82}$ Monotropic phase transitions are presented in parenthesis

\begin{tabular}{|c|c|c|c|c|c|c|c|c|c|c|c|c|}
\hline No & $n$ & $m$ & $\mathrm{Cr}$ & & $\mathrm{Sm}_{>}$ & & $\mathrm{SmA}_{2}$ & & $\mathrm{~N}_{\mathrm{TB}}$ & & $\mathrm{N}$ & Iso \\
\hline 83 & 9 & 2 & - & 92.9 & - & - & - & - & $(\bullet$ & 28.4) & - 167.2 & - \\
\hline 84 & 11 & 1 & - & 76.1 & $(\bullet$ & 57.1 & - & $67.0)$ & - & - & - 148.3 & - \\
\hline 85 & 11 & 2 & - & 79.8 & $(\bullet$ & 58.3 & - & 66.7 & - & 68.4) & - 162.1 & - \\
\hline 86 & 11 & 3 & - & 74.1 & $(\bullet$ & 73.6) & - & 91.9 & 一 & - & - 159.6 & - \\
\hline 87 & 11 & 4 & - & 74.2 & $(\bullet$ & 61.5 & $\bullet$ & $80.4)$ & - & - & - 158.6 & - \\
\hline 88 & 12 & 2 & - & 108.7 & - & - & $(\bullet$ & 99.9) & - & - & - 158.2 & - \\
\hline
\end{tabular}

probable, that other members of the FFOnOCB series of materials will be found to exhibit the $\mathrm{N}_{\mathrm{TB}}$ phase (Table 18). ${ }^{113}$

Replacement of the 2,4'-difluorobiphenyl unit employed in 97 (FFO11OCB) with other fluorinated biphenyls (Table 19) has some impact on the transition temperatures, with all but 101 exhibiting the nematic and nematic twist-bend phases. Clearly there are a significant number of combinations of mesogenic unit and spacer length that can give rise to the twist-bend phase in ether-linked materials.

3.2.2. Imine linked dimers. Šepelj et al. presented a series of 4-alkoxybenzoylsalicylaldimine dimers in (Table 20) with two members found to exhibit a nematic/nematic phase transition. ${ }^{91}$ This nematic/nematic phase transition was identified as being a columnar nematic mesophase in the original work; however, it is possible that this mesophase is actually the $\mathrm{N}_{\mathrm{TB}}$ phase. The presented optical textures for the salicylaldimine dimers are certainly in keeping with twist-bend nematic; however, this is a speculative result and not a definitive conclusion and merits further study.

Šepelj et al. later reported a homologous series of symmetrical, imine-linked phenyl 4-alkoxybenzoate dimers (Table 21), the majority of which exhibited the columnar-like B6 $^{\prime}$ mesophase. Compounds 114 (5-4) and 120 (7-4), which have the shortest terminal alkoxy chains in the series, also exhibit an additional nematic phase, with 120 exhibiting a nematic to nematic (termed $\mathrm{N}_{\mathrm{X}}$ in ref. 92) transition. Ivšić et al. revisited compound 120 and identified the lower temperature nematic phase as the $\mathrm{N}_{\mathrm{TB}}$ phase, ${ }^{104}$ although on the basis of a ${ }^{1} \mathrm{H}-{ }^{1} \mathrm{H}$ 
Table 17 Transition temperatures $\left({ }^{\circ} \mathrm{C}\right)$, of ether linked bimesogens with various mesogenic units. Monotropic phase transitions are presented in parenthesis ${ }^{79,82}$

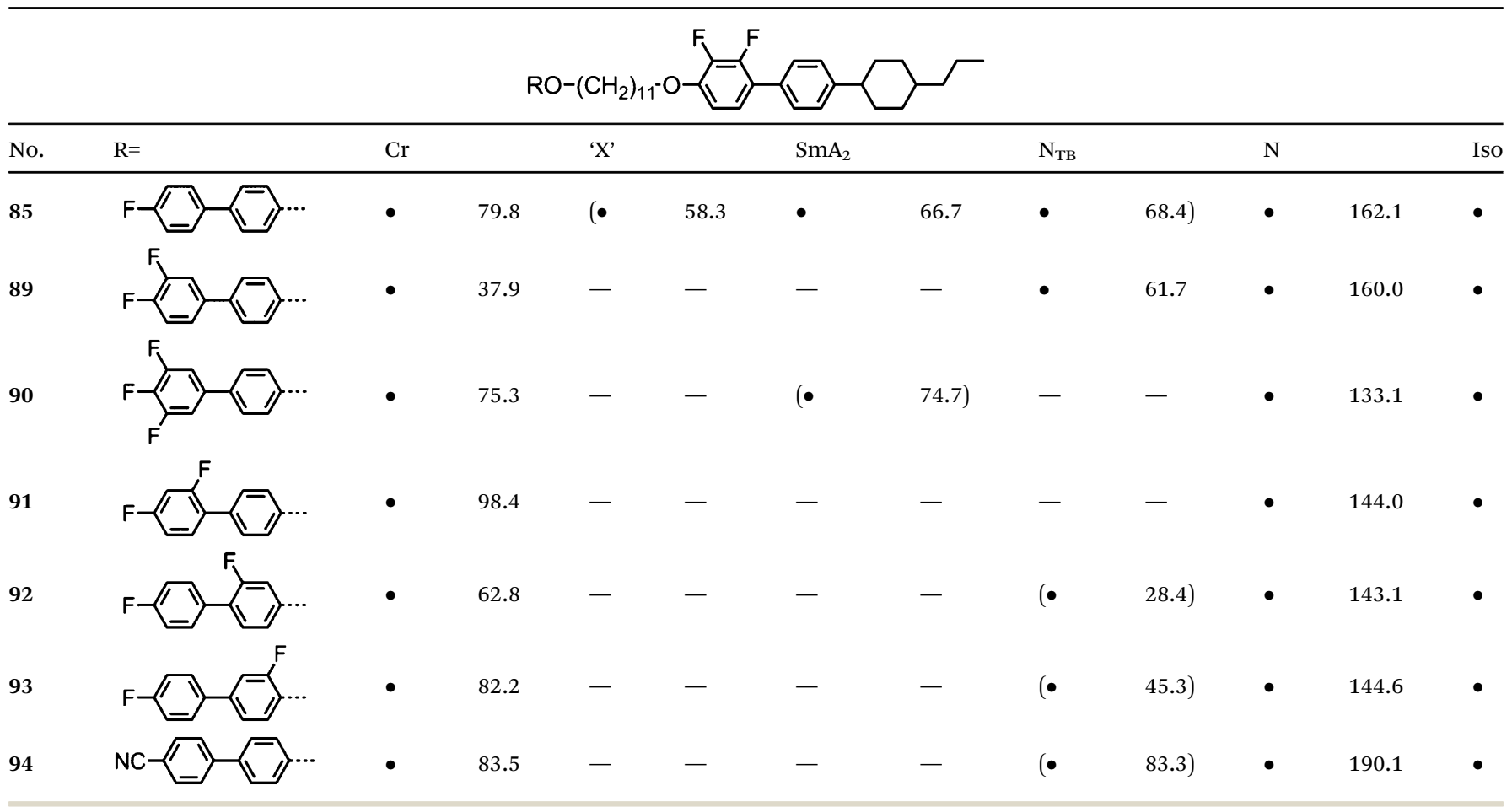

Table 18 Transition temperatures $\left({ }^{\circ} \mathrm{C}\right)$ reported for compounds 95 (FFO8OCB) 96 (FFO9OCB), and 97 (FFO11OCB). ${ }^{59,79,112}$ Monotropic phase transitions are presented in parenthesis

$\begin{array}{lllllllllll} & & & & \end{array}$

NOESY experiment they suggest an alternate structural model for this phase featuring local domains of syn packed dimers. The identification of the $\mathrm{N}_{\mathrm{TB}}$ phase in compounds 114 and 120 supports the idea that the lower-temperature nematic phase exhibited by the structurally similar materials in Table 20 is the $\mathrm{N}_{\mathrm{TB}}$ rather than a columnar nematic phase.

Incorporation of a naphthyl unit in place of the outermost phenyl ring of the materials presented in Tables 20 and 21 affords 126-129 (Table 22). In all cases the clearing points and melting points have increased relative to the parent phenyl materials as a consequence of the now increased aspect ratio of the individual mesogenic units. Only one material (128) was found to exhibit the twist-bend nematic phase, with others exhibiting $\mathrm{B}_{6}$ and rectangular columnar mesophases. Materials with even spacer parity (i.e. $m=6, m=8$ ) were also prepared and found to exhibit both modulated and intercalated smectic $\mathrm{A}$ and $\mathrm{C}$ mesophases.

Knowing that shorter terminal chains favour nematic and $\mathrm{N}_{\mathrm{TB}}$ mesophases Dawood et al. reported the synthesis
Table 19 Transition temperatures $\left({ }^{\circ} \mathrm{C}\right)$ reported for compounds $\mathbf{9 8 - 1 0 1} .^{79}$ Monotropic phase transitions are presented in parenthesis

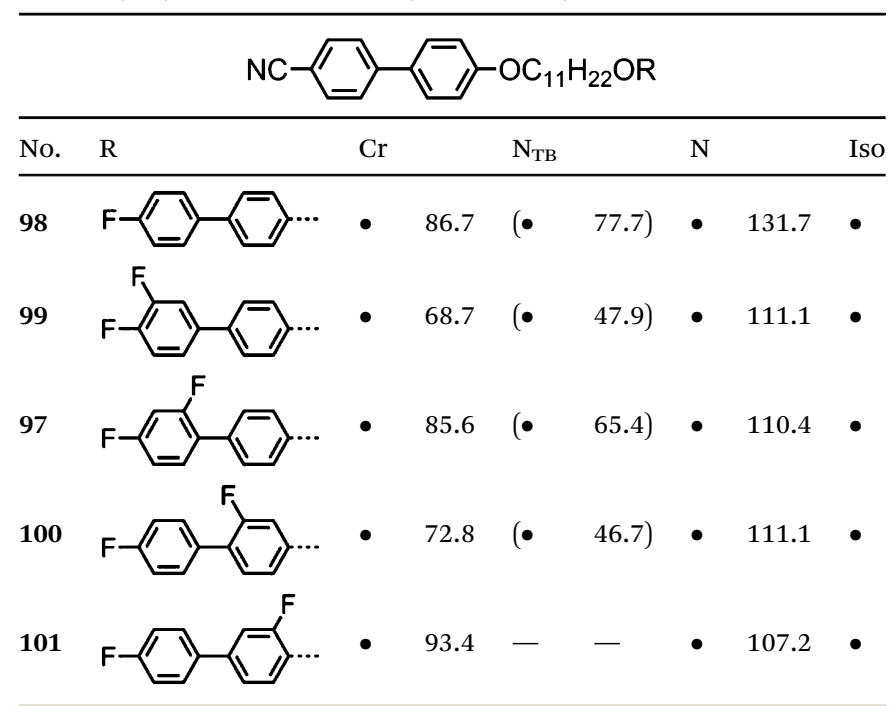

and characterisation of five symmetrical, imine linked phenyl 4-ethoxybenzoate dimers with varying central spacer length (Table 23). The homologue with the shortest central spacer (130, 2O-3-O2) exhibits a direct isotropic to twist-bend nematic phase transition, this being the first observation of this transition in a pure compound, which had first been observed in a binary mixture. $^{70}$

Three symmetrical dimers with cyanobiphenyl mesogenic units and imine linking groups have been reported. For these compounds there are sizable increases in the melting 
Table 20 Transition temperatures $\left({ }^{\circ} \mathrm{C}\right)$ of salicylaldimine dimers with odd spacer parity. ${ }^{91}$ Monotropic phase transitions are presented in parenthesis

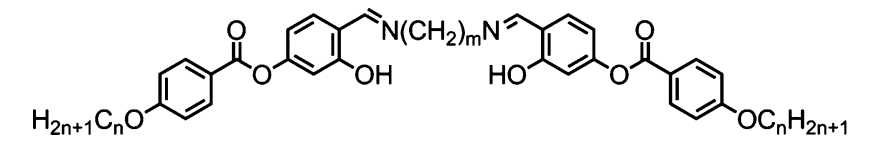

\begin{tabular}{|c|c|c|c|c|c|c|c|c|c|c|c|c|c|c|}
\hline No & Name & $n$ & $m$ & $\mathrm{Cr}$ & & $\mathrm{M}_{\mathrm{X}}$ & & $\mathrm{Col}_{\text {rec }}$ & & $\mathrm{N}_{\text {col }}$ & & $\mathrm{N}$ & & Iso \\
\hline 102 & $5-4$ & 4 & 5 & $\bullet$ & 106 & - & - & - & - & - & - & $(\bullet$ & 102) & 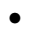 \\
\hline 103 & $5-6$ & 6 & 5 & $\bullet$ & 113 & - & - & - & - & $(\bullet$ & 87 & $\bullet$ & 97) & $\bullet$ \\
\hline 104 & $5-8$ & 8 & 5 & $\bullet$ & 103 & - & - & $(\bullet$ & 99) & - & - & $(\bullet$ & 102) & \\
\hline 105 & $5-10$ & 10 & 5 & $\bullet$ & 105 & - & - & $\bullet$ & 111 & - & - & - & - & $\bullet$ \\
\hline 106 & $5-12$ & 12 & 5 & $\bullet$ & 107 & - & - & $\bullet$ & 116 & - & - & - & - & $\bullet$ \\
\hline 107 & $5-14$ & 14 & 5 & $\bullet$ & 105 & $\bullet$ & 114 & $\bullet$ & 120 & - & - & - & - & $\bullet$ \\
\hline 108 & $7-4$ & 4 & 7 & $\bullet$ & 119 & - & - & - & - & - & & $\bullet$ & 121 & 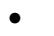 \\
\hline 109 & $7-6$ & 6 & 7 & $\bullet$ & 98 & - & - & - & - & $(\bullet$ & 93) & $\bullet$ & 113 & 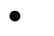 \\
\hline 110 & $7-8$ & 8 & 7 & $\bullet$ & 103 & - & - & - & - & - & - & $\bullet$ & 110 & 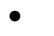 \\
\hline 111 & $7-10$ & 10 & 7 & $\bullet$ & 97 & - & - & $\bullet$ & 106 & - & - & $\bullet$ & 108 & \\
\hline 112 & $7-12$ & 12 & 7 & $\bullet$ & 100 & - & - & $\bullet$ & 112 & - & - & - & - & $\bullet$ \\
\hline 113 & $7-14$ & 14 & 7 & $\bullet$ & 99 & - & - & $\bullet$ & 117 & - & - & - & - & $\bullet$ \\
\hline
\end{tabular}

Table 21 Transition temperatures $\left({ }^{\circ} \mathrm{C}\right)$ of imine-linked phenyl 4-alkoxybenzoate dimers (114-125). ${ }^{92,103,104}$ Monotropic phase transitions are presented in parenthesis

\begin{tabular}{|c|c|c|c|c|c|c|c|c|c|c|c|c|}
\hline No & Name & $n$ & $m$ & $\mathrm{Cr}$ & & $\mathrm{B} 6^{\prime}$ & & $\mathrm{N}_{\mathrm{TB}}$ & & $\mathrm{N}$ & & Iso \\
\hline 114 & $5-4$ & 4 & 5 & • & 114.0 & $(\bullet$ & 99.1 & - & - & $\bullet$ & 102.0) & • \\
\hline 115 & 5-6 & 6 & 5 & • & 123.5 & $\bullet$ & 116.9) & - & - & - & - & - \\
\hline 116 & $5-8$ & 8 & 5 & • & 94.2 & $\bullet$ & 121.0 & - & - & - & - & - \\
\hline 117 & $5-10$ & 10 & 5 & • & 88.5 & • & 109.5 & - & - & - & - & - \\
\hline 118 & $5-12$ & 12 & 5 & • & 96.2 & • & 96.1 & - & - & - & - & $\bullet$ \\
\hline 119 & $5-14$ & 14 & 5 & • & 101.2 & - & - & - & - & - & - & • \\
\hline 120 & $7-4$ & 4 & 7 & • & 112.2 & $(\bullet$ & 84.4 & • & 96.6) & - & 115.0 & • \\
\hline 121 & $7-6$ & 6 & 7 & • & 96.4 & $\bullet$ & 114.7 & - & - & - & - & - \\
\hline 122 & $7-8$ & 8 & 7 & • & 111.2 & • & 119.5 & - & - & - & - & • \\
\hline 123 & $7-10$ & 10 & 7 & • & 100.1 & • & 110.1 & - & - & - & - & • \\
\hline 124 & $7-12$ & 12 & 7 & • & 90.9 & - & 99.3 & - & - & - & - & • \\
\hline 125 & $7-14$ & 14 & 7 & - & 73.3 & - & - & - & - & - & - & • \\
\hline
\end{tabular}

point, clearing point and $\mathrm{N}-\mathrm{N}_{\mathrm{TB}}$ transition temperature when compared to the analogous $\mathrm{CB} n \mathrm{CB}$ materials can be directly attributed to the change in conformational distribution that results from the incorporation of an imine (Table 24)..$^{104,106,115}$
Table 23 Transitions of the $2 \mathrm{O}-n-\mathrm{O} 2$ materials (130-134) reported by Dawood et al. ${ }^{71}$ Monotropic phase transitions are presented in parenthesis

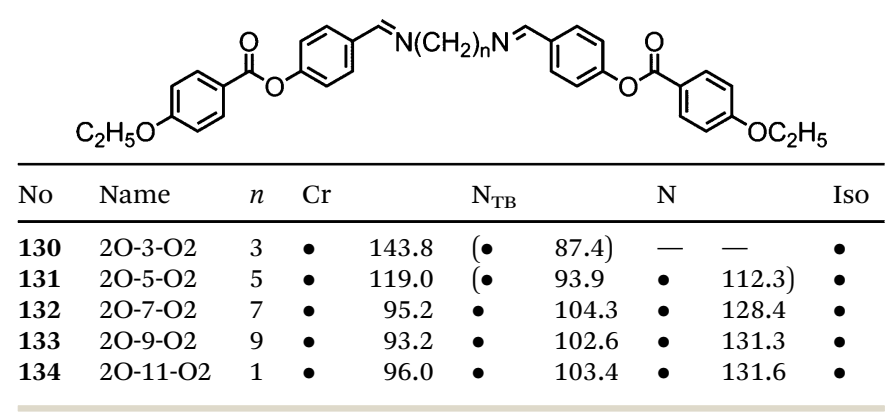

3.2.3. Dimers with mixed linking groups. Examples of both methylene- and ether-linked dimers that exhibit the $\mathrm{N}_{\mathrm{TB}}$ phase are known, and so it is perhaps unsurprising that mixed ethermethylene linked systems have also been found to form the $\mathrm{N}_{\mathrm{TB}}$ phase. Recently Paterson et al. reported 138 (CB6OABOBu) which, exhibits both nematic and twist-bend nematic mesophases when the azo group is in its trans geometry. Irradiation of the material in the twist-bend nematic phase with UV light (365 nm) leads to isomerisation of the azo linking group and an isothermal transition to the nematic phase occurs (Fig. 9). ${ }^{80}$

Replacement of a single methylene unit in $\mathrm{CB} 7 \mathrm{CB}$ to afford 139 (CB6OCB) or CB9CB to afford 140 (CB8OCB) leads to significant increases in both melting and clearing points, with a small increase in the nematic to twist-bend nematic transition temperature (Table 25). For 139 the helical pitch was measured to be $8.9 \mathrm{~nm}$ by FFTEM, which is close to the structurally related CB7CB $(\sim 8 \mathrm{~nm}),{ }^{116}$ however for 140 such data has not been reported. For both materials the clearing points and nematic to $\mathrm{N}_{\mathrm{TB}}$ transition temperatures are essentially identical.

A dimethylene group has some degree of flexibility whereas an alkyne is rigid and the replacement of the first two methylene units of compounds 139 and 140 with an alkyne affords compounds 141 and 142 respectively (Fig. 10), the latter having significantly increased melting points compared to those of the parent dimethylene materials. For 141 the clearing point and $\mathrm{N}-\mathrm{N}_{\mathrm{TB}}$ transition temperature are significantly reduced when compared to $\mathbf{1 3 9}$, while for $\mathbf{1 4 2}$ there is only a marginally reduced $\mathrm{N}-\mathrm{N}_{\mathrm{TB}}$ transition temperature with the clearing point being essentially identical to that of 140. The large difference in the $\mathrm{N}-\mathrm{N}_{\mathrm{TB}}$ transition temperatures of compounds 141 and 142,

Table 22 Transition temperatures $\left({ }^{\circ} \mathrm{C}\right)$ of the imine linked naphthyl-based dimers (126-129). ${ }^{114}$ Monotropic phase transitions are presented in parenthesis

\begin{tabular}{|c|c|c|c|c|c|c|c|c|c|c|c|c|c|c|c|}
\hline No & Name & $n$ & $m$ & $\mathrm{X}$ & $\mathrm{Cr}$ & & $\mathrm{Col}_{\mathrm{I}}$ & & $\mathrm{B}_{6}$ & & $\mathrm{~N}_{\mathrm{TB}}$ & & $\mathrm{N}$ & & Iso \\
\hline 126 & NB_7-8 & 8 & 7 & $\mathrm{H}$ & - & 120 & - & - & - & 167 & - & - & - & - & - \\
\hline 127 & NB_7-12 & 12 & 7 & $\mathrm{H}$ & - & 118 & - & - & - & 128 & - & - & - & - & - \\
\hline
\end{tabular}


Table 24 Transition temperatures $\left({ }^{\circ} \mathrm{C}\right)$ of imine linked cyanobiphenyl dimers (135-137). ${ }^{104,106,115}$ Monotropic phase transitions are presented in parenthesis

\begin{tabular}{|c|c|c|c|c|c|c|c|c|c|}
\hline No & Name & $n$ & $\mathrm{Cr}$ & & $\mathrm{N}_{\mathrm{col}}$ & & $\mathrm{N}$ & & Iso \\
\hline 135 & CBI-5-ICB & 5 & - & 140.8 & - & 114.7 & - & 138.7 & - \\
\hline 136 & CBI-7-ICB & 7 & - & 117 & - & 123 & - & 149 & - \\
\hline 137 & CBI-9-ICB & 9 & - & 113 & - & 126 & • & 153 & - \\
\hline
\end{tabular}

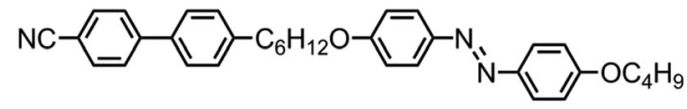

138: $\quad \operatorname{Cr} 104.8 \mathrm{~N}_{\mathrm{TB}} 105.5 \mathrm{~N} 152.7$

Fig. 9 The molecular structure and transition temperature of 138 ( $\mathrm{CB} 6 \mathrm{OABOBu})$, reported by Paterson et al. ${ }^{80}$

Table 25 Transition temperatures $\left({ }^{\circ} \mathrm{C}\right)$ of the $\mathrm{CBnOCB}$ dimers 139 and 140. ${ }^{115,116}$ Monotropic phase transitions are presented in parenthesis

\begin{tabular}{llllllllllll}
\hline & & & & & & &
\end{tabular}

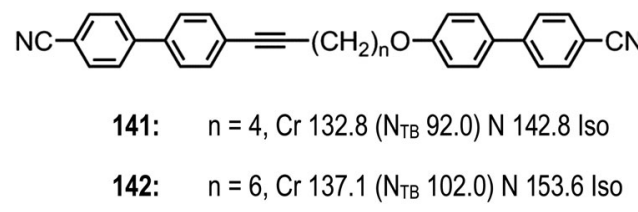

Fig. 10 The molecular structure and transition temperature of compounds 141 (CBCC4OCB) $)^{117}$ and 142 (CBCC6OCB). ${ }^{115}$ Phase transitions are presented in parenthesis are monotropic.

which is not present in the analogous 139 and 140, indicates that the flexibility of the spacer is significant - the inflexible alkyne occupying a greater proportion of the spacer length in 141 than in 142. This apparent sensitivity of the twist-bend nematic phase to the flexibility of the spacer supports the observation that the $\mathrm{N}_{\mathrm{TB}}$ phase is relatively common in mesogenic dimers and relatively rare in bent-core liquid crystals, the latter being typically regarded as rigid. $^{31}$

\subsection{Bent core systems}

A series of asymmetric, rigid bent-core materials with a central phenyl piperazine group were prepared by Schroder et al., ${ }^{118}$ with shorter homologues exhibiting a nematic-nematic phase transition. Later, compound $\mathbf{1 4 5}$ was revisited and the second nematic phase identified as being the $\mathrm{N}_{\mathrm{TB}}$ phase, the helical pitch $\left(\mathrm{P}_{\mathrm{TB}}\right)$ was measured by FFTEM to be $14 \mathrm{~nm}$ - larger than CB7CB, but still extremely short. ${ }^{19}$ Based on this it seems likely that the lower temperature nematic phase exhibited by compounds 143 and 144 is also the $\mathrm{N}_{\mathrm{TB}}$ phase. To date these, along with compound 153 (Fig. 11), are the only known examples of bent-core materials that exhibit the twist-bend nematic phase, although others have been suggested previously (Table 26). ${ }^{119}$

Tamba et al. reported a hybrid, ether-linked bent-core/calamitic dimer that exhibited the twist-bend nematic phase as well as an unidentified ' $\mathrm{M}_{2}$ ' mesophase. ${ }^{120}$ While variants featuring other spacer lengths (trimethylenoxy or hexamethylenoxy) or a dodecyloxy terminal chain in lieu of the nitrile unit employed in 153 were still liquid-crystalline, these no longer exhibit the twist-bend nematic phase.

\subsection{Chiral systems}

Several unsymmetrical, ester-linked cholesterol/ $N$-phenyl-4-alkylbenzimine bimesogens with odd-spacer parity were found to form nematic and twist-bend nematic phases, with even-parity homologues being solely nematogenic (i.e. they only exhibit a nematic phase) or exhibiting an additional smectic A phase.

The mesophase behaviour of compounds 154-161 is more complex than depicted in Table 27; while on heating the materials exhibit chiral nematic phases on cooling blue phases are seen instead, leading to direct $\mathrm{BP}-\mathrm{N}_{\mathrm{T}}$ phase transitions. In the case of compound $\mathbf{1 6 1}$ a total of six distinct phase transitions are seen by DSC over a $2{ }^{\circ} \mathrm{C}$ temperature range at the $\mathrm{N}^{*}-\mathrm{N}_{\text {Tв }}$ phase transition (Fig. 12). The $\mathrm{N}_{\mathrm{TB}}$ pitch length of 154 was measured by AFM and reported to be $50 \mathrm{~nm}$; significantly larger than that reported for $\mathrm{CB} 7 \mathrm{CB}$, but despite this difference in pitch, these two materials were found to be miscible at all concentrations. ${ }^{54,96}$

In general, azo linked materials (Table 28) have lower melting points than the analogous imine linked materials<smiles>CCCCOc1ccc(C(=O)Oc2ccc(C(=O)Oc3ccc(OC(=O)c4cccc(OC(=O)c5ccc(OC(=O)c6ccc(OCCCC)cc6)cc5)c4)cc3)cc2)cc1</smiles>

153: $\mathrm{Cr} 136\left(\mathrm{M}_{2} 109 \mathrm{~N}_{\mathrm{TB}} 115\right) \mathrm{N} 145$ Iso

Fig. 11 Chemical structure and transition temperatures of the hybrid bent-core/calamitic dimer reported by Tamba et al. ${ }^{120}$ Phase transitions are presented in parenthesis are monotropic. 


\begin{tabular}{|c|c|c|c|c|c|c|c|c|c|c|c|c|}
\hline No & $n$ & $\mathrm{Cr}$ & & SmCP & & $\mathrm{Col}_{2}$ & & $\mathrm{~N}_{\mathrm{X}} / \mathrm{N}_{\mathrm{TB}}$ & & $\mathrm{N}$ & & Iso \\
\hline 143 & 4 & $\bullet$ & 201 & - & - & - & - & $(\bullet$ & 193) & • & 212 & $\bullet$ \\
\hline 144 & 5 & • & 187 & - & - & - & - & $(\bullet$ & 172) & • & 192 & • \\
\hline 145 & 6 & $\bullet$ & 176 & - & - & $(\bullet$ & 157 & $\bullet$ & 169) & • & 188 & $\bullet$ \\
\hline 146 & 7 & $\bullet$ & 169 & - & - & - & - & - & - & $\bullet$ & 186 & $\bullet$ \\
\hline 147 & 8 & $\bullet$ & 177 & $\bullet$ & 180 & - & - & - & - & $\bullet$ & 180.5 & $\bullet$ \\
\hline 148 & 9 & • & 167 & $\bullet$ & 185 & - & - & - & - & - & - & $\bullet$ \\
\hline 149 & 10 & $\bullet$ & 162 & • & 191 & - & - & - & - & - & - & - \\
\hline 150 & 11 & • & 161 & • & 194 & - & - & - & - & - & - & $\bullet$ \\
\hline 151 & 12 & • & 165 & $\bullet$ & 201 & - & - & - & - & - & - & $\bullet$ \\
\hline 152 & 16 & $\bullet$ & 142 & $\bullet$ & 193 & - & - & - & - & - & - & $\bullet$ \\
\hline
\end{tabular}

(e.g. 156/165, 158/168, 159/169 and 161/170), while the clearing points and $\mathrm{N}-\mathrm{N}_{\mathrm{TB}}$ transitions remain approximately the same. In the case of compound $\mathbf{1 7 0}$ a transition from the nematic into an unknown smectic mesophase $\left(\mathrm{Sm}_{\mathrm{X}}\right)$ was reported, whereas the parent imine material exhibits a twist-bend nematic phase. The photochemical behaviour of these materials was not commented upon; however, it would appear reasonable to speculate that the photo-isomerisable azo linkage will result in a isothermal twist-bend nematic phase transition. ${ }^{80}$

Archibald et al. constructed a binary phase diagram between the dimer 58 and the chiral dopant BDH1281 (Fig. 13), at and above a dopant concentration of $5.5 \mathrm{wt} \%$ a direct isotropic to $\mathrm{N}_{\mathrm{TB}}$ phase transition was observed. ${ }^{43}$ Additionally at and above $5.2 \mathrm{wt} \%$ of BDH1281 a transition from the twist-bend nematic

Table 27 Transition temperatures $\left(^{\circ}\right)$ of the ester linked, unsymmetrical bimesogens (154-164) reported by Zep et al. and Gorecka et al. ${ }^{54,96}$ Monotropic phase transitions are presented in parenthesis

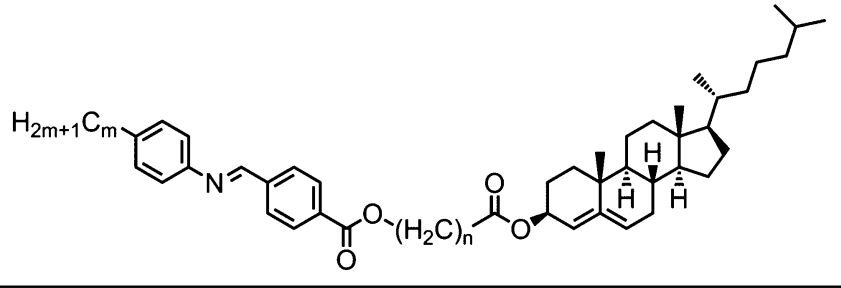

\begin{tabular}{|c|c|c|c|c|c|c|c|c|c|c|c|}
\hline No & Name & $n$ & $m$ & $\mathrm{Cr}$ & & $\mathrm{SmA}$ & & $\mathrm{N}_{\mathrm{TB}}$ & & $\mathrm{N}^{*}$ & \\
\hline 154 & SB $1 / 3$ & 3 & 1 & $\bullet$ & 112.3 & - & - & $(\bullet$ & 55.1 & 67.7) & \\
\hline 155 & SB $1 / 4$ & 4 & 1 & • & 127.9 & $\bullet$ & 146.9 & - & - & 191.8 & \\
\hline 156 & SB $1 / 5$ & 5 & 1 & $\bullet$ & 92.5 & - & - & $(\bullet$ & 67.9) & 102.3 & \\
\hline 157 & SB $1 / 6$ & 6 & 1 & $\bullet$ & 152.3 & $(\bullet$ & $120.0)$ & - & - & 158.4 & \\
\hline 158 & SB $1 / 7$ & 7 & 1 & - & 83.0 & - & - & $(\bullet$ & 75.7) & 110.8 & \\
\hline 159 & SB $1 / 9$ & 9 & 1 & $\bullet$ & 81.2 & - & - & (• & 75.7) & 113.6 & \\
\hline 160 & SB $1 / 10$ & 10 & 1 & - & 82.7 & - & - & - & - & 137.5 & \\
\hline 161 & SB $1 / 15$ & 15 & 1 & • & 62.9 & - & - & $(\bullet$ & $63.2)$ & 107.9 & \\
\hline 162 & SB $2 / 5$ & 5 & 2 & $\bullet$ & 74.0 & - & - & $(\bullet$ & $60.6)$ & 93.6 & \\
\hline 163 & SB $3 / 5$ & 5 & 3 & $\bullet$ & 77.5 & - & - & $(\bullet$ & $62.2)$ & 98.8 & \\
\hline 164 & SB $4 / 5$ & 5 & 4 & $\bullet$ & 44.2 & $\bullet$ & 71.9 & - & - & 99.3 & \\
\hline
\end{tabular}

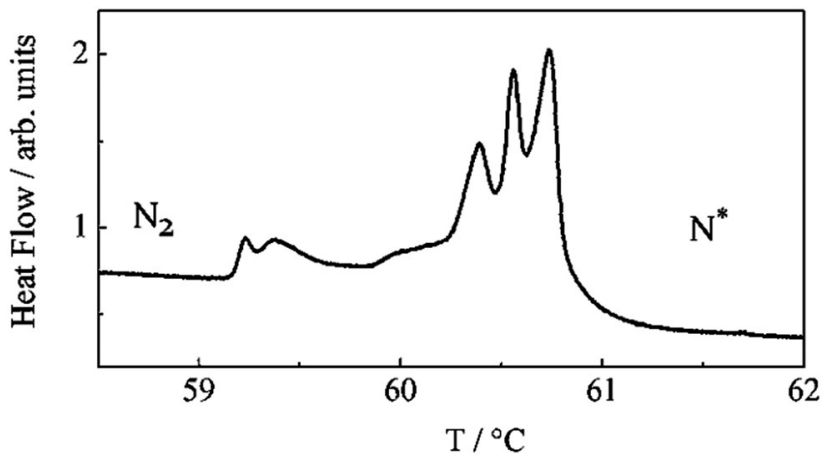

Fig. 12 High-resolution DSC thermogram for 161, showing multiple phase transitions between the $\mathrm{N}^{*}$ and $\mathrm{N}_{2}\left(\mathrm{~N}_{\mathrm{TB}}\right)$ mesophases. Reproduced from ref. 96 with permission of the Royal Society of Chemistry.

to a lower temperature mesophase lacking lamellar order (hence $\mathrm{N}_{\mathrm{X}}$ ) was also observed; the possibility of this mesophase being a splay-bend nematic was hinted at, but this is speculative and lacking experimental confirmation presently, perhaps by small angle or grazing incidence X-ray scattering as suggested by Zhu. ${ }^{50}$ The dopant/dimer mixtures also exhibit an apparent phase transition between two isotropic liquids which was postulated to be due to the formation of supermolecular aggregates. ${ }^{70}$ Mixtures containing below $5.5 \mathrm{wt} \%$ of the chiral dopant exhibit wide temperature range $\left(>5{ }^{\circ} \mathrm{C}\right)$ blue phases in analogy to those reported previously for mixtures of bimesogens and the dopant BDH1281 (Table 29). ${ }^{121}$

\subsection{Oligomers: trimers and tetramers}

Liquid-crystalline trimers are aptly named, being molecular entities comprised of three interconnected mesogenic units. ${ }^{122,123}$ The manner of the attachment need not be linear, ${ }^{124}$ and the mesogenic units are not strictly limited to rod-like groups. ${ }^{125}$ Liquid-crystalline tetramers can be defined as discrete molecules containing four interconnected mesogenic units. Whereas there 
Table 28 Transition temperatures $\left(^{\circ}\right)$ of the ester linked, unsymmetrical bimesogens $\left(\mathbf{1 6 5 - 1 7 0 )}\right.$ reported by Gorecka et al. ${ }^{54}$ Monotropic phase transitions are presented in parenthesis

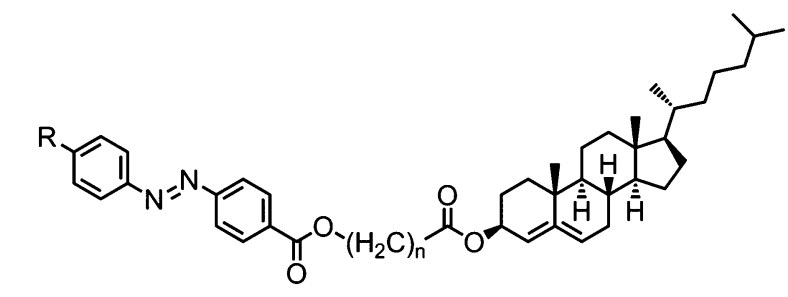

\begin{tabular}{|c|c|c|c|c|c|c|c|c|c|c|c|}
\hline No & Name & $n$ & $\mathrm{R}$ & $\mathrm{Cr}$ & & $\mathrm{Sm}_{\mathrm{x}}$ & & $\mathrm{N}_{\mathrm{TB}}$ & & $\mathrm{N}$ & \\
\hline 165 & Azo $1 / 5$ & 5 & $-\mathrm{CH}_{3}$ & - & 83.4 & - & - & $(\bullet$ & 67.1) & 105.5 & \\
\hline 166 & Azo $01 / 5$ & 5 & $-\mathrm{OCH}_{3}$ & - & 84.3 & - & - & $(\bullet$ & $80.8)$ & - 124.9 & \\
\hline 167 & Azo O2/5 & 5 & $-\mathrm{OC}_{2} \mathrm{H}_{5}$ & - & 107.0 & $(\bullet$ & 97.6) & - & - & - 134.4 & 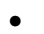 \\
\hline 168 & Azo 1/7 & 7 & $-\mathrm{CH}_{3}$ & - & 63.9 & - & - & $\bullet$ & 74.0 & - 111.5 & \\
\hline 169 & Azo 1/9 & 9 & $-\mathrm{CH}_{3}$ & - & 69.6 & - & - & - & 75.8 & - 113.6 & \\
\hline 170 & Azo 1/15 & 15 & $-\mathrm{CH}_{3}$ & - & 60.5 & $(\bullet$ & $60.3)$ & & - & - 100.3 & \\
\hline
\end{tabular}

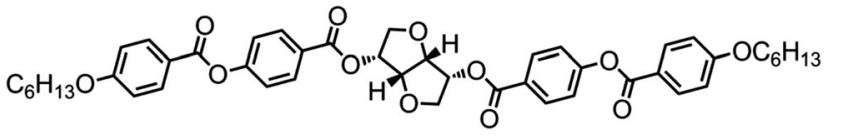

Cr 141.7 (SmA 137.6) Iso

Fig. 13 Molecular structure and transition temperatures $\left({ }^{\circ} \mathrm{C}\right)$ of the dianhydro-D-glucitol derived chiral dopant (BDH1281) used by Archibald et al. ${ }^{70}$ Monotropic phase transitions are presented in parenthesis.

are numerous examples of liquid-crystalline trimers, relatively few tetramers have been reported. ${ }^{126-129}$ Linear higher oligomers pose synthetic challenges, chiefly as efficient chromatographic purification is challenging, however some examples of pentamers exist. $^{130,131}$

In the context of the twist-bend nematic phase relatively few oligomeric materials are known to exhibit this state of matter. The hydrogen-bonded trimer formed spontaneously by $\mathbf{1 7 2}$ (CB6OBA, Table 30) was the first trimeric twist-bend nematogen to be reported; the analogue with even spacer parity, 171,
(CB5OBA) does not exhibit the twist-bend nematic phase. As the carboxylic acid group contains both a hydrogen bond donor and acceptor both 'open' and 'closed' H-bonded structures are possible. Variable temperature FT-IR has been used to examine the dynamic equilibrium that exists between free acid, 'open' dimers with one H-bond and 'closed' dimers with two H-bonds. ${ }^{93,132}$

As far as we are aware, the hybrid calamitic/bent core trimer 173 (Table 31) is only the second example of a twist-bend nematic material where the prerequisite bent shape arises not from a flexible spacer but rather a rigid unit (the other being 145). Values of the orientational order parameters $\left\langle P_{2}\right\rangle$ and $\left\langle P_{4}\right\rangle$ of 173 were determined by SAXS using the method of Davidson, ${ }^{133}$ which is incidentally known to be flawed, ${ }^{134}$ with the behaviour as a function of temperature across both the nematic and twist-bend nematic phases being to be consistent with those later obtained by PRS by Zhang et al. for the $\mathrm{CB} n \mathrm{CB}$ materials. ${ }^{55}$ The $d$-spacing of the diffuse small angle peak in both the nematic and $\mathrm{N}_{\text {TВ }}$ phases was approximately one third of the molecular length, indicating that both phases are intercalated. The pitch of the $\mathrm{N}_{\mathrm{TB}}$ phase of $\mathbf{1 7 3}$ was determined by FFTEM according to the method used by Chen et al. ${ }^{48}$ giving a value of $\sim 19 \mathrm{~nm}$ which corresponds to approximately four molecular lengths. ${ }^{49}$ When one of the cyanobiphenyl units is replaced with a decyloxy chain the resulting material exhibits nematic and biaxial smectic A mesophases, but not the twistbend nematic. $^{135}$

The symmetrical, linear trimer 174 (Table 32) exhibits nematic and twist-bend nematic mesophases, as does the related tetrameric compound 176 (T4, , Table 33). ${ }^{77,95}$ When studied by SAXS the diffuse small angle scattering peak observed in both the nematic and $\mathrm{N}_{\mathrm{TB}}$ phases occurs at roughly 0.33 molecular lengths for $\mathbf{1 7 4}$ and 0.25 molecular lengths for 176 (58.0 ̊ and $62.8 \AA$ respectively), ${ }^{95}$ confirming that for both materials the lower temperature mesophase is not lamellar but nematic as well as demonstrating that the mesophases are extensively intercalated, as was reported by Wang et al. for the trimer $173 .{ }^{49}$ The associated enthalpy of the $\mathrm{N}_{\mathrm{TB}}-\mathrm{N}$

Table 29 Transition temperatures $\left({ }^{\circ} \mathrm{C} \text { ) of binary mixtures of compound } \mathbf{5 8} \text { (structure above) and the chiral dopant BDH1281 (Fig. } 13\right)^{70}$

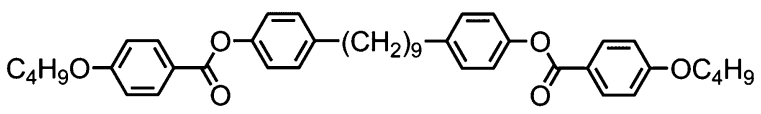

\begin{tabular}{|c|c|c|c|c|c|c|c|c|c|c|c|c|c|}
\hline Wt\% BDH1281 & $\mathrm{Cr}$ & & $\mathrm{N}_{\mathrm{X}}$ & & $\mathrm{N}_{\mathrm{T} 1}$ & & $\mathrm{~N}^{*}$ & & BPII & & $\mathrm{ISO}_{1}$ & & $\mathrm{IsO}_{2}$ \\
\hline $0^{a}$ & $\bullet$ & 83.3 & - & - & $\bullet$ & 84.7 & $\bullet$ & 99.5 & - & - & $\bullet$ & - & - \\
\hline 0.6 & $\bullet$ & 80.9 & - & - & $\bullet$ & 82.2 & $\bullet$ & 83.4 & $\bullet$ & 95.3 & $\bullet$ & 98.6 & $\bullet$ \\
\hline 2.1 & $\bullet$ & 80.5 & - & - & $\bullet$ & 82.4 & $\bullet$ & 82.5 & $\bullet$ & 95.3 & $\bullet$ & 98.4 & $\bullet$ \\
\hline 4.7 & $\bullet$ & 79.5 & - & - & $\bullet$ & 82.1 & $\bullet$ & 82.3 & $\bullet$ & 91.6 & $\bullet$ & 98.1 & $\bullet$ \\
\hline 5.2 & $\bullet$ & 79.5 & $(\bullet$ & 62.1) & $\bullet$ & 83.5 & $\bullet$ & 83.6 & $\bullet$ & 92.7 & $\bullet$ & 97.3 & $\bullet$ \\
\hline 5.4 & $\bullet$ & 79.5 & $(\bullet$ & 66.1) & $\bullet$ & 83.3 & $\bullet$ & 83.4 & $\bullet$ & 88.6 & $\bullet$ & 96.6 & $\bullet$ \\
\hline 5.5 & $\bullet$ & 79.4 & $(\bullet$ & $67.2)$ & $\bullet$ & 83.2 & - & - & - & - & $\bullet$ & 96.8 & $\bullet$ \\
\hline 6.5 & $\bullet$ & 79.3 & $(\bullet$ & 66.4) & $\bullet$ & 83.4 & - & - & - & - & $\bullet$ & 96.4 & $\bullet$ \\
\hline 7.1 & $\bullet$ & 79.4 & $(\bullet$ & $67.2)$ & $\bullet$ & 82.3 & - & - & - & - & $\bullet$ & 96.4 & $\bullet$ \\
\hline 8.4 & $\bullet$ & 79.1 & $(\bullet$ & 68.3) & $\bullet$ & 81.9 & - & - & - & - & $\bullet$ & 95.3 & $\bullet$ \\
\hline 9.8 & $\bullet$ & 79.2 & $(\bullet$ & 69.6) & $\bullet$ & 79.2 & - & - & - & - & $\bullet$ & 96.5 & $\bullet$ \\
\hline
\end{tabular}

${ }^{a}$ Note, the nematic phase exhibited in the absence of a chiral dopant is achiral. Monotropic phase transitions are presented in parenthesis. 
Table 30 Transition temperatures $\left({ }^{\circ} \mathrm{C}\right)$ of the hydrogen-bonded trimers 171 (CB5OCB, linear) and 172 (CB6OBA, bent). ${ }^{97}$ Monotropic phase transitions are presented in parenthesis

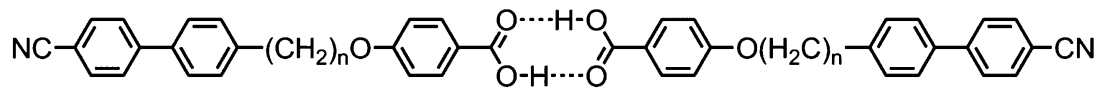

\begin{tabular}{|c|c|c|c|c|c|c|c|c|c|}
\hline No & Name & $n$ & $\mathrm{Cr}$ & & $\mathrm{N}_{\mathrm{TB}}$ & & $\mathrm{N}$ & & Iso \\
\hline 171 & CB5OBA & 5 & $\bullet$ & 196 & - & - & $\bullet$ & 209 & $\bullet$ \\
\hline 172 & CB6OCB & 6 & $\bullet$ & 160 & $(\bullet$ & 159) & $\bullet$ & 197 & $\bullet$ \\
\hline
\end{tabular}

Table 31 Transition temperatures $\left({ }^{\circ} \mathrm{C}\right)$ of the hybrid calamitic/bent core trimer 173

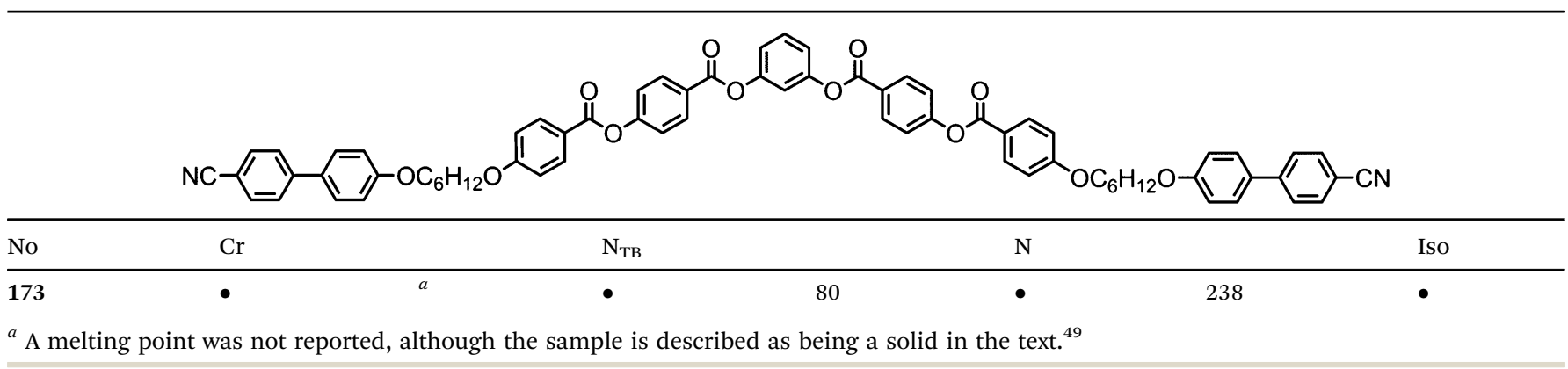

transition is typically much smaller than the N-Iso transition, and this is also observed for the trimer 175. In the case of the tetramer 176 the associated enthalpy of the $\mathrm{N}_{\mathrm{TB}}-\mathrm{N}$ transition is somewhat larger than that of the clearing point, with both transitions being strongly first-order.

The tetramer $\mathbf{1 7 7}$ was also found to exhibit nematic and twist-bend nematic mesophases. Unlike $\mathbf{1 7 6}$ this material lacks strongly polar terminal groups, instead having butoxy chains, while the spacers used are slightly shorter $\left(\mathrm{C}_{7} v s . \mathrm{C}_{9}\right)$. Additionally the two 'central' mesogenic units have different aspect ratios to the 'outer' units. When studied by SAXS, as with other oligomeric twist-bend materials, the diffuse small angle scattering peak that corresponds to the molecular length is approximately $1 / 4$ th of the molecular length, demonstrating that both the nematic and $\mathrm{N}_{\mathrm{TB}}$ phases are extensively intercalated, while the lack of sharp peaks confirms the two mesophases are not lamellar. It seems reasonable to conclude that many combinations of terminal chain length, central spacer length and mesogenic unit composition will give rise to the twist-bend nematic phase in oligomeric materials (Table 34 ).

\section{Summary and outlook}

The experimental observation of the predicted twist-bend nematic phase has led to a renewed interest in liquidcrystalline dimers. The number of materials known to exhibit a twist-bend nematic phase has increased significantly since the experimental discovery of this state of matter, with around 90 materials, many of which were prepared by the materials

Table 32 Transition temperatures $\left({ }^{\circ} \mathrm{C}\right)$ of the trimer $174^{95}$

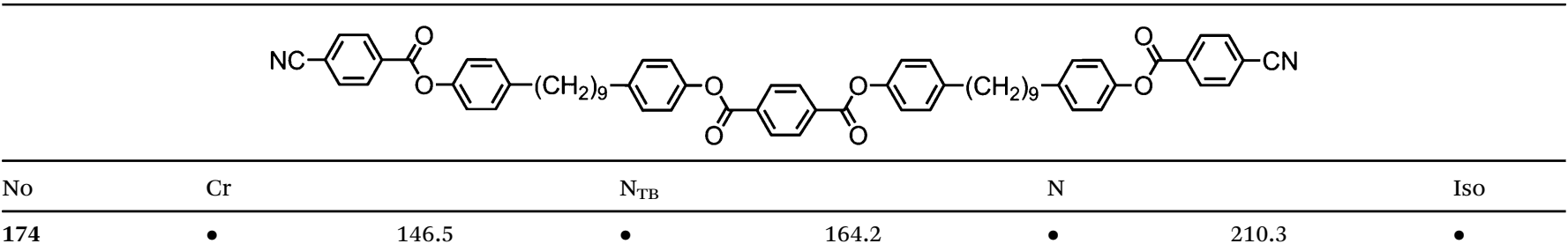

Table 33 Transition temperatures $\left({ }^{\circ} \mathrm{C}\right)$ of the tetramer $176\left(\mathrm{~T} 4_{9}\right)^{77,95}$

$\frac{\mathrm{No} \quad \mathrm{Name}}{176} \quad \mathrm{Cr}$


Table 34 Transition temperatures $\left({ }^{\circ} \mathrm{C}\right)$ of the tetramer $177\left(4 \mathrm{O}_{7}\right)^{136}$

\begin{tabular}{|c|c|c|c|c|c|c|c|c|}
\hline No & Name & $\mathrm{Cr}$ & & $\mathrm{N}_{\mathrm{TB}}$ & & $\mathrm{N}$ & & Iso \\
\hline 177 & $4 \mathrm{O}_{7}$ & • & 153.4 & - & 173.5 & $\bullet$ & 193.2 & - \\
\hline
\end{tabular}

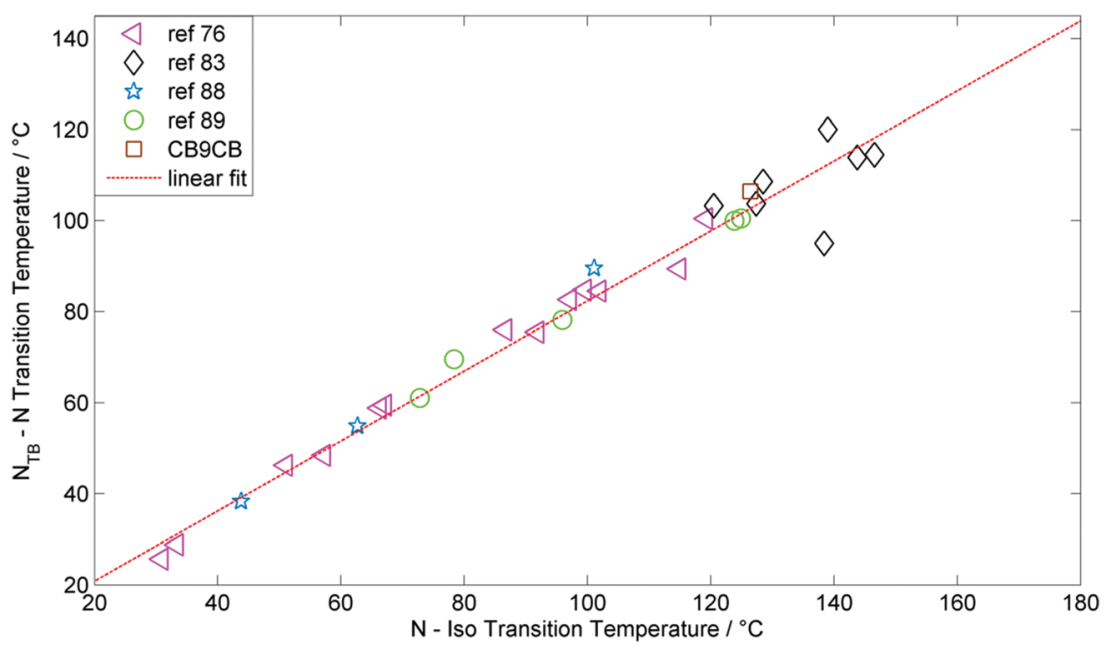

Fig. 14 Plot of the nematic to isotropic transition temperature $\left({ }^{\circ} \mathrm{C}\right)$ versus the twist-bend nematic to nematic transition temperature $\left({ }^{\circ} \mathrm{C}\right)$ for dimers and bimesogens with 'two-ring' mesogenic units and nonamethylene spacer. The $R^{2}$ value of the linear fit is 0.975 . Data was taken from ref. $55,76,83$, 94 and 95.

group at York, now known to exhibit this mesophase. Several examples of twist-bend nematic phases formed by lower oligomers (trimers and tetramers), and there is every reason to believe that examples of higher oligomers and polymers that generate the $\mathrm{N}_{\mathrm{TB}}$ phase will be found. Indeed, the lower temperature nematic phase observed in copolymers exhibiting a nematic-nematic phase transition has been suggested to be a twist-bend nematic phase. ${ }^{137}$ The synthesis of the tetramer 177 is performed in such a way that the individual mesogenic units are installed one-by-one, meaning that the synthesis of higher oligomers of analogous molecular structure may be achievable. A general and definitive structure property relationship remains elusive; however, a gross bent molecular shape is seemingly required and the molecular flexibility appears important as well. The incidence of the twist-bend nematic phase is not especially dependent on combinations of functional groups etc., provided the prerequisite bent shape is satisfied.

The largest sub-group to exhibit the twist-bend nematic phase are methylene linked with a nonamethylene spacer and mesogenic units constructed of two rigid cyclic units, with around 40 materials known in total. For these materials that there is linear relationship between the N-I transition temperature $\left(T_{\mathrm{N}-\mathrm{I}}\right)$ and the $\mathrm{N}_{\mathrm{TB}}-\mathrm{N}$ transition temperature $\left(T_{\mathrm{N}-\mathrm{N}_{\mathrm{TB}}}\right.$, plot given in Fig. 14). This plot contains materials having both polar and non-polar terminal groups as well as both symmetric and unsymmetrical dimers. It must also be noted that in the case of materials having terminal alkyl/alkoxy chains the length of these groups has, apparently, no significant influence on the relationship between $T_{\mathrm{N}-\mathrm{I}}$ and $T_{\mathrm{N}-\mathrm{N}_{\mathrm{TB}}}$. Analogous materials with different spacer lengths or different aspect ratios for the individual mesogenic units yield different slopes, however the liner relationship is retained. In essence, the temperature at which the nematic or twist-bend nematic phase transition occurs are dependent on one another and are therefore somewhat independent of molecular structure, i.e. the exact values of each phase transition depend on the chemical makeup of a given material but the relationship between these transitions does not.

Transitions from the twist-bend nematic to smectic phases are rare, although examples exist, and it is worth speculating as to whether or not re-entrant $\mathrm{N}_{\mathrm{TB}}$ phases can exist; examples of both re-entrant nematic and re-entrant smectic phases in dimers have been reported, ${ }^{138,139}$ but to date such behaviour has not been observed for the $\mathrm{N}_{\mathrm{TB}}$ phase.

\section{Acknowledgements}

I would like to thank Professor John Goodby FRS, Dr Edward Davis, Dr Stephen Cowling, Dr Mark Sims and Mr Craig Archbold for many useful discussions concerning dimers and oligomers in the context of the $\mathrm{N}_{\mathrm{TB}}$ phase, as well as for assistance in preparing this article. I would also like to extend this gratitude to my current and former students, namely 
Constantin Voll, Sam Lobato, Dan Lewis, Phillip Foeller, Jess Andrews, Frank Simpson and Matthew Stevens, for undertaking projects work on dimers and twist-bend nematics.

\section{References}

1 A. C. Neville and B. M. Luke, J. Cell Sci., 1971, 8, 93-109.

2 Y. M. Yevdokimov, S. G. Skuridin and V. I. Salyanov, Liq. Cryst., 1988, 3, 1443-1459.

3 F. Livolant, A. M. Levelut, J. Doucet and J. P. Benoit, Nature, 1989, 339, 724-726.

4 F. P. Booy, W. W. Newcomb, B. L. Trus, J. C. Brown, T. S. Baker and A. C. Steven, Cell, 1991, 64, 1007-1015.

5 Z. Reich, E. J. Wachtel and A. Minsky, Science, 1994, 264, 1460-1463.

6 S. Mangenot, A. Leforestier, D. Durand and F. Livolant, J. Mol. Biol., 2003, 333, 907-916.

7 P. Bault, P. Gode, G. Goethals, J. W. Goodby, J. A. Haley, S. M. Kelly, G. H. Mehl, G. Ronco and P. Villa, Liq. Cryst., 1998, 25, 31-45.

8 J. W. Goodby, Liq. Cryst., 2006, 33, 1229-1237.

9 R. Xu, F. Ali-Rachedi, N. M. Xavier, S. Chambert, F. Ferkous, Y. Queneau, S. J. Cowling, E. J. Davis and J. W. Goodby, Org. Biomol. Chem., 2015, 13, 783-792.

10 J. Watanabe, Y. Fukuda, R. Gehani and I. Uematsu, Macromolecules, 1984, 17, 1004-1009.

11 J. Watanabe, H. Ono, I. Uematsu and A. Abe, Macromolecules, 1985, 18, 2141-2148.

12 E. Iizuka, S. Inoue, K. Hanabusa and H. Shirai, Mol. Cryst. Liq. Cryst., 1987, 149, 61-77.

13 S. Fraden, G. Maret, D. L. D. Caspar and R. B. Meyer, Phys. Rev. Lett., 1989, 63, 2068-2071.

14 S. Fraden, G. Maret and D. L. D. Caspar, Phys. Rev. E: Stat. Phys., Plasmas, Fluids, Relat. Interdiscip. Top., 1993, 48, 2816-2837.

15 S. Zhou, A. Sokolov, O. D. Lavrentovich and I. S. Aranson, Proc. Natl. Acad. Sci. U. S. A., 2014, 111, 1265-1270.

16 I. Dozov, Europhys. Lett., 2001, 56, 247-253.

17 M. Cestari, S. Diez-Berart, D. A. Dunmur, A. Ferrarini, M. R. de la Fuente, D. J. B. Jackson, D. O. Lopez, G. R. Luckhurst, M. A. Perez-Jubindo, R. M. Richardson, J. Salud, B. A. Timimi and H. Zimmermann, Phys. Rev. E: Stat., Nonlinear, Soft Matter Phys., 2011, 84, 031704.

18 V. Borshch, Y. K. Kim, J. Xiang, M. Gao, A. Jakli, V. P. Panov, J. K. Vij, C. T. Imrie, M. G. Tamba, G. H. Mehl and O. D. Lavrentovich, Nat. Commun., 2013, 4, 1-8.

19 D. Chen, M. Nakata, R. F. Shao, M. R. Tuchband, M. Shuai, U. Baumeister, W. Weissflog, D. M. Walba, M. A. Glaser, J. E. Maclennan and N. A. Clark, Phys. Rev. E: Stat., Nonlinear, Soft Matter Phys., 2014, 89, 022506.

20 K. Soai, T. Shibata, H. Morioka and K. Choji, Nature, 1995, 378, 767-768.

21 V. Avetisov and V. Goldanskii, Proc. Natl. Acad. Sci. U. S. A., 1996, 93, 11435-11442.

22 S. J. Sowerby, W. M. Heckl and G. B. Petersen, J. Mol. Evol., 1996, 43, 419-424.
23 M. Bolli, R. Micura and A. Eschenmoser, Chem. Biol., 1997, 4, 309-320.

24 J. Bailey, A. Chrysostomou, J. H. Hough, T. M. Gledhill, A. McCall, S. Clark, F. Menard and M. Tamura, Science, 1998, 281, 672-674.

25 C. Viedma, Astrobiology, 2007, 7, 312-319.

26 M. Alaasar, M. Prehm and C. Tschierske, Chem. - Eur. J., 2016, 22, 6583-6597.

27 H. Sasaki, Y. Takanishi, J. Yamamoto and A. Yoshizawa, Soft Matter, 2016, 12, 3331-3339.

28 J. Sniechowska, P. Paluch, G. Bujacz, M. Gorecki, J. Frelek, D. T. Gryko and M. J. Potrzebowski, CrystEngComm, 2016, 18, 3561-3565.

29 C. Tschierske and G. Ungar, ChemPhysChem, 2016, 17, 9-26.

30 D. R. Link, G. Natale, R. Shao, J. E. Maclennan, N. A. Clark, E. Korblova and D. M. Walba, Science, 1997, 278, 1924-1927.

31 R. A. Reddy and C. Tschierske, J. Mater. Chem., 2006, 16, 907-961.

32 H. Takezoe and Y. Takanishi, Jpn. J. Appl. Phys., Part 1, 2006, 45, 597-625.

33 L. Beguin, J. W. Emsley, M. Lelli, A. Lesage, G. R. Luckhurst, B. A. Timimi and H. Zimmermann, J. Phys. Chem. B, 2012, 116, 10407.

34 J. W. Emsley, M. Lelli, A. Lesage and G. R. Luckhurst, J. Phys. Chem. B, 2013, 117, 6547-6557.

35 J. W. Emsley, P. Lesot, G. R. Luckhurst, A. Meddour and D. Merlet, Phys. Rev. E: Stat., Nonlinear, Soft Matter Phys., 2013, 87, 040501.

36 C. Greco, G. R. Luckhurst and A. Ferrarini, Phys. Chem. Chem. Phys., 2013, 15, 14961-14965.

37 H. Takezoe, Top. Curr. Chem., 2012, 318, 303-330.

38 A. Yoshizawa, Y. Kato, H. Sasaki, Y. Takanishi and J. Yamamoto, Soft Matter, 2015, 11, 8827-8833.

39 A. Yoshizawa, Y. Kato, H. Sasaki, Y. Takanishi and J. Yamamoto, J. Phys. Chem. B, 2016, 120, 4843-4851.

40 C. Greco, G. R. Luckhurst and A. Ferrarini, Soft Matter, 2014, 10, 9318-9323.

41 C. Greco and A. Ferrarini, Phys. Rev. Lett., 2015, 115, 147801.

42 C. Meyer and I. Dozov, Soft Matter, 2016, 12, 574-580.

43 A. G. Vanakaras and D. J. Photinos, Soft Matter, 2016, 12, 2208-2220.

44 D. O. Lopez, B. Robles-Hernandez, J. Salud, M. R. de la Fuente, N. Sebastian, S. Diez-Berart, X. Jaen, D. A. Dunmur and G. R. Luckhurst, Phys. Chem. Chem. Phys., 2016, 18, 4394-4404.

45 K. S. Krishnamurthy, P. Kumar, N. B. Palakurthy, C. V. Yelamaggad and E. G. Virga, Soft Matter, 2016, 12, 4967-4978.

46 S. A. Pardaev, S. M. Shamid, M. G. Tamba, C. Welch, G. H. Mehl, J. T. Gleeson, D. W. Allender, J. V. Selinger, B. Ellman, A. Jakli and S. Sprunt, Soft Matter, 2016, 12, 4472-4482.

47 C. T. Imrie and P. A. Henderson, Chem. Soc. Rev., 2007, 36, 2096-2124. 
48 D. Chen, J. H. Porada, J. B. Hooper, A. Klittnick, Y. Q. Shen, M. R. Tuchband, E. Korblova, D. Bedrov, D. M. Walba, M. A. Glaser, J. E. Maclennan and N. A. Clark, Proc. Natl. Acad. Sci. U. S. A., 2013, 110, 15931-15936.

49 Y. Wang, G. Singh, D. M. Agra-Kooijman, M. Gao, H. K. Bisoyi, C. M. Xue, M. R. Fisch, S. Kumar and Q. Li, CrystEngComm, 2015, 17, 2778-2782.

50 C. H. Zhu, M. R. Tuchband, A. Young, M. Shuai, A. Scarbrough, D. M. Walba, J. E. Maclennan, C. Wang, A. Hexemer and N. A. Clark, Phys. Rev. Lett., 2016, 116, 147803.

51 C. Meyer, G. R. Luckhurst and I. Dozov, Phys. Rev. Lett., 2013, 111, 067801.

52 C. Meyer, G. R. Luckhurst and I. Dozov, J. Mater. Chem. C, 2015, 3, 318-328.

53 J. P. Jokisaari, G. R. Luckhurst, B. A. Timimi, J. F. Zhu and H. Zimmermann, Liq. Cryst., 2015, 42, 708-721.

54 E. Gorecka, N. Vaupotic, A. Zep, D. Pociecha, J. Yoshioka, J. Yamamoto and H. Takezoe, Angew. Chem., Int. Ed., 2015, 54, 10155-10159.

55 Z. P. Zhang, V. P. Panov, M. Nagaraj, R. J. Mandle, J. W. Goodby, G. R. Luckhurst, J. C. Jones and H. F. Gleeson, J. Mater. Chem. C, 2015, 3, 10007-10016.

56 P. J. Barnes, A. G. Douglass, S. K. Heeks and G. R. Luckhurst, Liq. Cryst., 1993, 13, 603-613.

57 D. O. Lopez, N. Sebastian, M. R. de la Fuente, J. C. Martinez-Garcia, J. Salud, M. A. Perez-Jubindo, S. DiezBerart, D. A. Dunmur and G. R. Luckhurst, J. Chem. Phys., 2012, 137, 034502.

58 R. R. R. de Almeida, C. Zhang, O. Parri, S. N. Sprunt and A. Jakli, Liq. Cryst., 2014, 41, 1661-1667.

59 N. Sebastian, D. O. Lopez, B. Robles-Hernandez, M. R. de la Fuente, J. Salud, M. A. Perez-Jubindo, D. A. Dunmur, G. R. Luckhurst and D. J. B. Jackson, Phys. Chem. Chem. Phys., 2014, 16, 21391-21406.

60 B. Robles-Hernandez, N. Sebastian, M. R. de la Fuente, D. O. Lopez, S. Diez-Berart, J. Salud, M. B. Ros, D. A. Dunmur, G. R. Luckhurst and B. A. Timimi, Phys. Rev. E: Stat., Nonlinear, Soft Matter Phys., 2015, 92, 062505.

61 S. Parthasarathi, D. S. Rao, N. B. Palakurthy, C. V. Yelamaggad and S. Krishna Prasad, J. Phys. Chem. B, 2016, 120, 5056-5062.

62 K. Adlem, M. Copic, G. R. Luckhurst, A. Mertelj, O. Parri, R. M. Richardson, B. D. Snow, B. A. Timimi, R. P. Tuffin and D. Wilkes, Phys. Rev. E: Stat., Nonlinear, Soft Matter Phys., 2013, 88, 022503.

63 S. M. Salili, C. Kim, S. Sprunt, J. T. Gleeson, O. Parri and A. Jakli, RSC Adv., 2014, 4, 57419-57423.

64 J. W. Emsley, G. R. Luckhurst and G. N. Shilstone, Mol. Phys., 1984, 53, 1023-1028.

65 J. W. Emsley, G. R. Luckhurst, G. N. Shilstone and I. Sage, Mol. Cryst. Liq. Cryst., 1984, 102, 223-233.

66 R. J. Mandle, E. J. Davis, C. T. Archbold, S. J. Cowling and J. W. Goodby, J. Mater. Chem. C, 2014, 2, 556-566.

67 A. Hoffmann, A. G. Vanakaras, A. Kohlmeier, G. H. Mehl and D. J. Photinos, Soft Matter, 2015, 11, 850-855.
68 E. Gorecka, M. Salamonczyk, A. Zep, D. Pociecha, C. Welch, Z. Ahmed and G. H. Mehl, Liq. Cryst., 2015, 42, 1-7.

69 C. J. Yun, M. R. Vengatesan, J. K. Vij and J. K. Song, Appl. Phys. Lett., 2015, 106, 173102.

70 C. T. Archbold, E. J. Davis, R. J. Mandle, S. J. Cowling and J. W. Goodby, Soft Matter, 2015, 11, 7547-7557.

71 A. A. Dawood, M. C. Grossel, G. R. Luckhurst, R. M. Richardson, B. A. Timimi, N. J. Wells and Y. Z. Yousif, Liq. Cryst., 2016, 43, 2-12.

72 L. Beguin, J. W. Emsley, M. Lelli, A. Lesage, G. R. Luckhurst, B. A. Timimi and H. Zimmermann, J. Phys. Chem. B, 2012, 116, 7940-7951.

73 V. P. Panov, M. C. M. Varney, I. I. Smalyukh, J. K. Vij, M. G. Tamba and G. H. Mehl, Mol. Cryst. Liq. Cryst., 2015, 611, 180-185.

74 C. S. P. Tripathi, P. Losada-Perez, C. Glorieux, A. Kohlmeier, M. G. Tamba, G. H. Mehl and J. Leys, Phys. Rev. E: Stat., Nonlinear, Soft Matter Phys., 2011, 84, 041707.

75 V. P. Panov, M. Nagaraj, J. K. Vij, Y. P. Panarin, A. Kohlmeier, M. G. Tamba, R. A. Lewis and G. H. Mehl, Phys. Rev. Lett., 2010, 105, 167801.

76 R. J. Mandle, E. J. Davis, C. T. Archbold, C. C. A. Voll, J. L. Andrews, S. J. Cowling and J. W. Goodby, Chem. - Eur. J., 2015, 21, 8158-8167.

77 R. J. Mandle and J. W. Goodby, ChemPhysChem, 2016, 17, 967-970.

78 R. J. Mandle and J. W. Goodby, Soft Matter, 2016, 12, 1436-1443.

79 R. J. Mandle, C. C. A. Voll, D. J. Lewis and J. W. Goodby, Liq. Cryst., 2016, 43, 13-21.

80 D. A. Paterson, J. Xiang, G. Singh, R. Walker, D. M. Agra-Kooijman, A. Martinez-Felipe, M. Gan, J. M. D. Storey, S. Kumar, O. D. Lavrentovich and C. T. Imrie, J. Am. Chem. Soc., 2016, 138, 5283-5289.

81 E. Ramou, Z. Ahmed, C. Welch, P. K. Karahaliou and G. H. Mehl, Soft Matter, 2016, 12, 888-899.

82 R. J. Mandle, E. J. Davis, S. A. Lobato, C. C. A. Vol, S. J. Cowling and J. W. Goodby, Phys. Chem. Chem. Phys., 2014, 16, 6907-6915.

83 R. J. Mandle, E. J. Davis, C. C. A. Voll, C. T. Archbold, J. W. Goodby and S. J. Cowling, Liq. Cryst., 2015, 42, 688-703.

84 V. P. Panov, R. Balachandran, M. Nagaraj, J. K. Vij, M. G. Tamba, A. Kohlmeier and G. H. Mehl, Appl. Phys. Lett., 2011, 99, 261903.

85 M. Mathews, R. S. Zola, D.-k. Yang and Q. Li, J. Mater. Chem., 2011, 21, 2098-2103.

86 J. Xiang, Y. Li, Q. Li, D. A. Paterson, J. M. D. Storey, C. T. Imrie and O. D. Lavrentovich, Adv. Mater., 2015, 27, 3014-3018.

87 Y. Wang, Z.-g. Zheng, H. K. Bisoyi, K. G. Gutierrez-Cuevas, L. Wang, R. S. Zola and Q. Li, Mater. Horiz., 2016, 3, 442-446.

88 H. K. Bisoyi and Q. Li, Acc. Chem. Res., 2014, 47, 3184-3195. 89 L. Wang and Q. Li, Adv. Funct. Mater., 2016, 26, 10-28.

90 Z.-g. Zheng, Y. Li, H. K. Bisoyi, L. Wang, T. J. Bunning and Q. Li, Nature, 2016, 531, 352-356. 
91 M. Sepelj, A. Lesac, U. Baumeister, S. Diele, D. W. Bruce and Z. Hamersak, Chem. Mater., 2006, 18, 2050-2058.

92 M. Sepelj, A. Lesac, U. Baumeister, S. Diele, H. L. Nguyen and D. W. Bruce, J. Mater. Chem., 2007, 17, 1154-1165.

93 D. A. Paterson, A. Martinez-Felipe, S. M. Jansze, A. T. M. Marcelis, J. M. D. Storey and C. T. Imrie, Liq. Cryst., 2015, 42, 928-939.

94 Z. Ahmed, C. Welch and G. H. Mehl, RSC Adv., 2015, 5, 93513-93521.

95 R. J. Mandle and J. W. Goodby, RSC Adv., 2016, 6, 34885-34893.

96 A. Zep, S. Aya, K. Aihara, K. Ema, D. Pociecha, K. Madrak, P. Bernatowicz, H. Takezoe and E. Gorecka, J. Mater. Chem. C, 2013, 1, 46-49.

97 S. M. Jansze, A. Martinez-Felipe, J. M. D. Storey, A. T. M. Marcelis and C. T. Imrie, Angew. Chem., Int. Ed., 2015, 54, 643-646.

98 Z. B. Lu, P. A. Henderson, B. J. A. Paterson and C. T. Imrie, Liq. Cryst., 2014, 41, 471-483.

99 M. G. Tamba, S. M. Salili, C. Zhang, A. Jakli, G. H. Mehl, R. Stannarius and A. Eremin, RSC Adv., 2015, 5, 11207-11211.

100 N. Sebastian, M. G. Tamba, R. Stannarius, M. R. de la Fuente, M. Salamonczyk, G. Cukrov, J. Gleeson, S. Sprunt, A. Jakli, C. Welch, Z. Ahmed, G. H. Mehl and A. Eremin, Phys. Chem. Chem. Phys., 2016, DOI: 10.1039/c6cp03899a.

101 P. A. Henderson, O. Niemeyer and C. T. Imrie, Liq. Cryst., 2001, 28, 463-472.

102 P. A. Henderson and C. T. Imrie, Liq. Cryst., 2011, 38, 1407-1414.

103 T. Ivsic, M. Vinkovic, U. Baumeister, A. Mikleusevic and A. Lesac, Soft Matter, 2015, 11, 6716.

104 T. Ivsic, M. Vinkovic, U. Baumeister, A. Mikleusevic and A. Lesac, $R S C A d v .$, 2016, 6, 5000-5007.

105 K. J. Toyne, in Thermotropic Liquid Crystals, ed. G. W. Gray, Wiley, 1987, vol. 1, pp. 22-63.

106 R. J. Mandle and J. W. Goodby, Chemistry, 2016, 22, 9366-9374.

107 J. W. Goodby, E. J. Davis, R. J. Mandle and S. J. Cowling, Isr. J. Chem., 2012, 52, 863-880.

108 M. Cestari, E. Frezza, A. Ferrarini and G. R. Luckhurst, J. Mater. Chem., 2011, 21, 12303-12308.

109 S. M. Morris, M. J. Clarke, A. E. Blatch and H. J. Coles, Phys. Rev. E: Stat., Nonlinear, Soft Matter Phys., 2007, 75, 041701.

110 K. L. Atkinson, S. M. Morris, M. M. Qasim, F. Castles, D. J. Gardiner, P. J. W. Hands, S. S. Choi, W. S. Kim and H. J. Coles, Phys. Chem. Chem. Phys., 2012, 14, 16377-16385.

111 M. Stocchero, A. Ferrarini, G. J. Moro, D. A. Dunmur and G. R. Luckhurst, J. Chem. Phys., 2004, 121, 8079-8097.

112 K. L. Atkinson, S. M. Morris, F. Castles, M. M. Qasim, D. J. Gardiner and H. J. Coles, Phys. Rev. E: Stat., Nonlinear, Soft Matter Phys., 2012, 85, 012701.

113 H. J. Coles, M. J. Clarke, S. M. Morris, B. J. Broughton and A. E. Blatch, J. Appl. Phys., 2006, 99, 034104.
114 M. Sepelj, U. Baumeister, T. Ivsic and A. Lesac, J. Phys. Chem. B, 2013, 117, 8918-8929.

115 R. Mandle and J. W. Goodby, presented in part at the BLCS conference, Edinburgh, UK, 21/3/2016, 2016.

116 C. T. Imrie, D. A. Paterson, M. Gao, Y.-K. Kim, A. Jamali, K. Finley, D. O. Lopez, S. Diez-Berart, J. Salud, G. R. Luckhurst, O. D. Lavrentovich, J. M. D. Storey, M. R. de la Fuente, A. Ferrarini, C. Greco, H. Zimmermann, B. Timimi and B. Robles-Hernandez, Soft Matter, 2016, DOI: 10.1039/C6SM00537C.

117 F. R. Simpson and R. J. Mandle, unpublished results, 2016.

118 M. W. Schroder, S. Diele, G. Pelzl, U. Dunemann, H. Kresse and W. Weissflog, J. Mater. Chem., 2003, 13, 1877-1882.

119 V. Gortz, C. Southern, N. W. Roberts, H. F. Gleeson and J. W. Goodby, Soft Matter, 2009, 5, 463-471.

120 M. G. Tamba, U. Baumeister, G. Pelzl and W. Weissflog, Ferroelectrics, 2014, 468, 52-76.

121 H. J. Coles and M. N. Pivnenko, Nature, 2005, 436, 997-1000.

122 P. Keller, Mol. Cryst. Liq. Cryst., 1985, 123, 247-256.

123 C. T. Imrie and G. R. Luckhurst, J. Mater. Chem., 1998, 8, 1339-1343.

124 J. Andersch, S. Diele, D. Lose and C. Tschierske, Liq. Cryst., 1996, 21, 103-113.

125 W. Kreuder, H. Ringsdorf, O. Herrmannschonherr and J. H. Wendorff, Angew. Chem., Int. Ed. Engl., 1987, 26, 1249-1252.

126 A. C. Griffin, S. L. Sullivan and W. E. Hughes, Liq. Cryst., 1989, 4, 677-684.

127 C. T. Imrie, D. Stewart, C. Remy, D. W. Christie, I. W. Hamley and R. Harding, J. Mater. Chem., 1999, 9, 2321-2325.

128 C. V. Yelamaggad, S. A. Nagamani, U. S. Hiremath, D. S. S. Rao and S. K. Prasad, Liq. Cryst., 2002, 29, 231-236.

129 P. A. Henderson and C. T. Imrie, Macromolecules, 2005, 38, 3307-3311.

130 C. V. Yelamaggad, A. S. Achalkumar, D. S. S. Rao and S. K. Prasad, Org. Lett., 2007, 9, 2641-2644.

131 A. Yoshizawa, J. Mater. Chem., 2008, 18, 2877-2889.

132 A. Martinez-Felipe and C. T. Imrie, J. Mol. Struct., 2015, 1100, 429-437.

133 P. Davidson, D. Petermann and A. M. Levelut, J. Phys. II, 1995, 5, 113-131.

134 T. T. Mills, G. E. S. Toombes, S. Tristram-Nagle, D. M. Smilgies, G. W. Feigenson and J. F. Nagle, Biophys. J., 2008, 95, 669-681.

135 Y. Wang, H. G. Yoon, H. K. Bisoyi, S. Kumar and Q. Li, J. Mater. Chem., 2012, 22, 20363-20367.

136 M. R. J. Simpson F., 2016, unpublished results.

137 G. Ungar, V. Percec and M. Zuber, Macromolecules, 1992, 25, 75-80.

138 C. V. Yelamaggad, V. P. Tamilenthi, D. S. S. Rao, G. G. Nair and S. K. Prasad, J. Mater. Chem., 2009, 19, 2906-2908.

139 R. Prabhu and C. V. Yelamaggad, J. Phys. Chem. B, 2015, 119, 11935-11952. 